Old Dominion University

ODU Digital Commons

Engineering Technology Faculty Publications

Engineering Technology

2019

\title{
Comparison of Observed and Simulated Drop Size Distributions From Large Eddy Simulations With Bin Microphysics
}

Mikael K. White

Patrick Y. Chuang

Orlando Ayala

Old Dominion University, oayala@odu.edu

Lian-Ping Wang

Graham Feingold

Follow this and additional works at: https://digitalcommons.odu.edu/engtech_fac_pubs

Part of the Climate Commons

\section{Repository Citation}

White, Mikael K.; Chuang, Patrick Y.; Ayala, Orlando; Wang, Lian-Ping; and Feingold, Graham, "Comparison of Observed and Simulated Drop Size Distributions From Large Eddy Simulations With Bin Microphysics" (2019). Engineering Technology Faculty Publications. 128.

https://digitalcommons.odu.edu/engtech_fac_pubs/128

\section{Original Publication Citation}

Witte, M. K., Chuang, P. Y., Ayala, O., Wang, L.-P., \& Feingold, G. (2019). Comparison of observed and simulated drop size distributions from large-eddy simulations with bin microphysics. Monthly Weather Review, 147(2), 477-493. doi:10.1175/MWRD-18-0242.1 


\title{
Comparison of Observed and Simulated Drop Size Distributions from Large-Eddy Simulations with Bin Microphysics
}

\author{
MiKAEL K. WitTE \\ National Center for Atmospheric Research, Boulder, Colorado \\ PATRICK Y. CHUANG \\ Earth and Planetary Sciences, University of California, Santa Cruz, Santa Cruz, California \\ ORLANDO AYALA \\ Engineering Technology Department, Old Dominion University, Norfolk, Virginia \\ LIAN-PING WANG \\ Department of Mechanical Engineering, University of Delaware, Newark, Delaware, and Department of \\ Mechanics and Aerospace Engineering, Southern University of Science and Technology, Shenzhen, China \\ GRAHAM FEINGOLD \\ Chemical Sciences Division, NOAA/Earth System Research Laboratory, Boulder, Colorado
}

(Manuscript received 10 July 2018, in final form 2 November 2018)

\begin{abstract}
Two case studies of marine stratocumulus (one nocturnal and drizzling, the other daytime and nonprecipitating) are simulated by the UCLA large-eddy simulation model with bin microphysics for comparison with aircraft in situ observations. A high-bin-resolution variant of the microphysics is implemented for closer comparison with cloud drop size distribution (DSD) observations and a turbulent collision-coalescence kernel to evaluate the role of turbulence on drizzle formation. Simulations agree well with observational constraints, reproducing observed thermodynamic profiles (i.e., liquid water potential temperature and total moisture mixing ratio) as well as liquid water path. Cloud drop number concentration and liquid water content profiles also agree well insofar as the thermodynamic profiles match observations, but there are significant differences in DSD shape among simulations that cause discrepancies in higher-order moments such as sedimentation flux, especially as a function of bin resolution. Counterintuitively, high-bin-resolution simulations produce broader DSDs than standard resolution for both cases. Examination of several metrics of DSD width and percentile drop sizes shows that various discrepancies of model output with respect to the observations can be attributed to specific microphysical processes: condensation spuriously creates DSDs that are too wide as measured by standard deviation, which leads to collisional production of too many large drops. The turbulent kernel has the greatest impact on the low-binresolution simulation of the drizzling case, which exhibits greater surface precipitation accumulation and broader DSDs than the control (quiescent kernel) simulations. Turbulence effects on precipitation formation cannot be definitively evaluated using bin microphysics until the artificial condensation broadening issue has been addressed.
\end{abstract}

\section{Introduction}

Parameterizations of the microphysical processes responsible for clouds and precipitation are necessary in all numerical models of the atmosphere capable of

\footnotetext{
Corresponding author: Mikael K. Witte, mikael.k.witte@jpl. nasa.gov
}

producing realistic flows because of the wide range of spatial scales that must be represented. The convective circulations that drive cloud and precipitation formation in the planetary boundary layer (PBL) occur at the vertical scale of the PBL-from hundreds of meters to a few kilometers-while the microphysical processes that govern the evolution of cloud drops occur on scales as small as micrometers (i.e., the size of the drops 
themselves). Despite the necessity for microphysical parameterizations, there remain major unresolved questions regarding the representation of the relevant processes, such that clouds and their interaction with other components of the climate system are the leading source of uncertainty in projections of future climate (IPCC 2013).

The "bin" approach to microphysical parameterization, wherein the drop size distribution (DSD) is divided into discrete size bins and each bin is operated on individually, has been regarded as the standard to which other less complex schemes are compared, primarily because the shape of the DSD is allowed to freely evolve using a bin scheme (Khain et al. 2015). Results from large-eddy simulations (LES) with bin microphysics have also been used as the basis for estimating bulk parameterization process rates (Khairoutdinov and Kogan 2000). Despite the confidence placed in bin microphysics, few studies have sought to quantify the "realism" of bin microphysics output by comparing it with sizeresolved observations (either in situ or remotely sensed). Khairoutdinov and Kogan (1999, their Figs. 5 and 11) compared output from LES with bin microphysics against aircraft observations and found remarkably good qualitative agreement between simulated and observed DSDs in terms of matching mode diameter and DSD shape (specifically, the right tail of the DSD) despite using rather coarse vertical resolution for simulating stratocumulus $(\Delta z=25 \mathrm{~m})$. Their simulations were designed to match the observations over the final simulated hour, and no information on the temporal evolution of the simulations was given; thus, it is unclear whether the degree of model-observation agreement is indicative of robust model performance or if instead it was a fortunate transient. A more recent study by Rémillard et al. (2017) compared synthetic Doppler spectra from modeled DSDs with radar observations over the Azores and found that the two LES models used for the study produced too many of the largest drops. The present study compares size-resolved output of number concentration and mass mixing ratio with observations from aircraft in situ probes to evaluate the performance of a two-moment bin microphysics scheme over the course of 6-h simulations.

Specifically, we examine the ability of modeled warm clouds to initiate liquid precipitation. This topic, often referred to as the "warm rain problem" (Beard and Ochs 1993), has received considerable attention over the years. Collision-coalescence is the process responsible for growing drops from the small sizes attainable by condensation (drop diameter $d \sim 20-30 \mu \mathrm{m}$ ) to the size of rain drops observed at the surface $(d>1 \mathrm{~mm})$ on time scales commensurate with a single overturning of the PBL (15-20 min). A typical cloud drop $20 \mu \mathrm{m}$ in diameter must undergo over $10^{5}$ collisions to become a 1-mm raindrop in that time period. Many mechanisms have been proposed to explain how collision-coalescence initiation may be accelerated, such as heterogeneity by turbulent mixing (Baker and Latham 1979; Cooper et al. 2013), giant cloud condensation nuclei (Johnson 1982; Jensen and Nugent 2017), and direct augmentation of collision-coalescence rates by turbulence (Devenish et al. 2012; Grabowski and Wang 2013). Understanding which of these mechanisms, if any, contributes to bridging the size gap in which neither condensation nor collisioncoalescence is effective is best done with a process model such as LES with drop size-resolving microphysics. The model output can then be constrained by observations (e.g., in situ aircraft measurements). Here, we use LES with bin microphysics to gain a baseline understanding of the ability of the model to form precipitation and reproduce observed drop size distributions by simulating two case studies from the Physics of Stratocumulus Tops (POST) field program: one in drizzling conditions and the other nondrizzling. We then apply a turbulent collision-coalescence kernel to examine the ability of turbulence effects to accelerate the onset of collisioncoalescence in stratocumulus.

\section{Model description}

For our simulations, we use the University of California, Los Angeles, large-eddy simulation model (UCLA-LES; Stevens and Seifert 2008) with the standard configuration for dynamics, radiation, and subgrid diffusion: momentum advection is computed with a fourth-order centered scheme, scalar advection with a second-order monotonic flux-limited scheme, radiation with a delta-4 stream approximation (Pincus and Stevens 2009), and a Smagorinsky approach is used for explicit subgrid-scale mixing.

The model domain is $7.2 \times 7.2 \times 1.2 \mathrm{~km}^{3}$ with $\Delta x=50 \mathrm{~m}$ and boundary layer $\Delta z=5 \mathrm{~m}$ with a logarithmically stretched vertical grid above $600 \mathrm{~m}$; a total of $144^{2} \times 135$ grid points are used. A prescribed large-scale divergence of $3 \times 10^{-6} \mathrm{~s}^{-1}$ is applied, a comparable value to other modeling studies of northeast Pacific marine stratocumulus (e.g., Ackerman et al. 2004, 2009); simulation results are insensitive to this value within a factor of 2. Surface fluxes are prescribed for each case study (see section 3 and Table 1).

We use the Tel Aviv University two-moment bin microphysics scheme (Tzivion et al. 1987, 1989) in a similar configuration to that of Stevens et al. (1998), but we add the option to choose between two bin resolutions: the standard mass-doubling grid (logarithmic bin spacing factor $p=2,33$ bins; henceforth LO) or a high-resolution grid $\left(p=2^{1 / 4}, 132\right.$ bins; HI), which more closely matches 
TABLE 1. Prescribed parameters for the simulated cases. SHF is surface sensible heat flux, LHF is surface latent heat flux, SST is sea surface temperature, and $N_{a}$ is aerosol number mixing ratio. SHF, LHF, and SST are derived from observations, while $N_{a}$ is set to match typical observed cloud drop number concentration.

\begin{tabular}{lccccc}
\hline \hline Case & Date & SHF $\left(\mathrm{W} \mathrm{m}^{-2}\right)$ & LHF $\left(\mathrm{W} \mathrm{m}^{-2}\right)$ & $\mathrm{SST}(\mathrm{K})^{N_{a}\left(\mathrm{mg}^{-1}\right)}$ \\
\hline TO14 & 12 Aug 2008 & 6.4 & 17.7 & 286.1 & 125 \\
TO17 & 15 Aug 2008 & 1.5 & 3.8 & 285.8 & 110 \\
\hline
\end{tabular}

the bin resolution of the drop size distribution observations. In both cases, drop sizes span the range $3<d<1500 \mu \mathrm{m}$. UCLA-LES uses a third-order RungeKutta time stepping scheme for dynamics; the microphysics subroutine is called outside of the Runge-Kutta loop. In addition to reducing computational expense, this is consistent with how the microphysical forcing is calculated with respect to the dynamical tendency of supersaturation (Clark 1973; Stevens et al. 1996a).

The microphysics scheme is configured such that activation of cloud condensation nuclei $(\mathrm{CCN})$, condensation, evaporation, collision-coalescence, and sedimentation are considered; aerosol processing, drop breakup, and ice processes are neglected. Condensation and evaporation are performed with the "top hat" approximation method of Stevens et al. (1996a). This method assumes a uniform rectangular number/mass distribution of assumed width within each bin (hence "top hat"), translates the top hat distribution according to the analytic solution, and remaps the top hats to bins. For collisioncoalescence, the algorithm of Tzivion et al. (1987) is used for LO resolution and Tzivion et al. (1999) for HI resolution. We note that Tzivion et al. (1999) also discretize the stochastic collection equation for $p=2^{1 / 2}$ and $p=2^{1 / 3}$ grid spacings. Activation is handled as by Stevens et al. [(1996a, 1998); i.e., as a mass flux to the smallest drop bin with lognormally distributed constant CCN concentration (no aerosol processing)]; in these simulations, geometric mean diameter and standard deviation $\left(D_{g}, \sigma_{d}\right)=(0.12 \mu \mathrm{m}, 1.7)$. A first-order upwind scheme is used for sedimentation. For the simulations presented in this study, a "dry" start is prescribed (i.e., no liquid water is present at model startup).

Turbulence is coupled to collision-coalescence via the collision kernel $K$. Numerous parameterizations of turbulent collision-coalescence rates have been developed for use in dynamical models (Ayala et al. 2008b; Franklin 2008; Benmoshe et al. 2012; Chen et al. 2016; Onishi and Seifert 2016). We use the Ayala kernel (Ayala et al. 2008b), which extends the quiescent hydrodynamical kernel of Hall (1980) to account for the effects of microscale turbulence on the geometric collection kernel (Ayala et al. 2008b) and collision efficiency (Wang and Grabowski 2009). Turbulent enhancement of the kernel is parameterized as a function of the turbulent dissipation rate $\varepsilon$ [i.e., $K_{\text {Ayala }}\left(m_{1}, m_{2}, \varepsilon\right)$ ], which is calculated in the subgrid diffusion scheme as the product of eddy viscosity and strain rate.

Kernel coefficients for use in the collision-coalescence subroutine are calculated offline and stored in a lookup table. The Ayala kernel is explicitly defined from hybrid direct numerical simulation (DNS) at $\varepsilon=\{10,100,400\} \mathrm{cm}^{2} \mathrm{~s}^{-3}$ for the geometric collision kernel (Ayala et al. 2008a) and at $\varepsilon=\{100,400\}$ for collision efficiency (Wang and Grabowski 2009). To avoid repeated interpolation during runtime, Ayala kernel coefficients are generated by linear interpolation at discrete values of dissipation rate relevant to shallow convection $\varepsilon=\{0,10,30,50,100,300,400,600\} \mathrm{cm}^{2} \mathrm{~s}^{-3}$. The kernel value in a grid cell is then selected by rounding up $\varepsilon$ [e.g., for $10<\varepsilon \leq 30 \mathrm{~cm}^{2} \mathrm{~s}^{-3}, K(\varepsilon=30)$ ], with the exception that $K(\varepsilon<1)=K(0)$. The Ayala kernel reduces to the Hall kernel for $\varepsilon=0$. The "round up" approach leads to artificial acceleration of collision-coalescence rates because the Ayala kernel is a monotonically increasing function of $\varepsilon$ and thus will slightly overestimate turbulent collision-coalescence. Further uncertainty is introduced by the nonlinear dependence of the turbulent kernel on $\varepsilon$ and a lack of DNS-derived kernel values at the low dissipation rates prevalent in marine stratocumulus (typical $\bar{\varepsilon}<10 \mathrm{~cm}^{2} \mathrm{~s}^{-3}$; Siebert et al. 2010). DNS kernel results from lower $\varepsilon$ values are desirable to verify the interpolation approach. This study is not the first to implement the Ayala kernel in a dynamical model, although it is the first to focus on stratocumulus; other studies have implemented it for use with both bin and bulk microphysics schemes to simulate shallow cumulus (e.g., Seifert et al. 2010; Wyszogrodzki et al. 2013).

Simulations with four basic configurations are performed for each case study: standard mass-doubling spectral resolution with the standard, nonturbulent (or quiescent) collision kernel (default "control" configuration; LO-CTRL); standard resolution with the turbulent kernel (LO-TURB); high spectral resolution with the quiescent kernel (HI-CTRL); and high spectral resolution with the turbulent kernel (HI-TURB). In addition, simulations with only the condensation/evaporation subroutine activated (COND; i.e., no collision-coalescence 
or drop sedimentation) will also be used. All simulations are run for $6 \mathrm{~h}$, and, unless otherwise noted, the profiles presented are horizontal domain averages over the last $4 \mathrm{~h}$ of each simulation. The quiescent Hall kernel is always used during the first hour of simulation time, at which point simulations branch into CTRL and TURB variants. This is done to avoid spuriously large collisioncoalescence rates during model spinup, when $\varepsilon$ can fluctuate widely. In all figures where results from simulations are presented, blue represents LO-resolution simulations, and red represents HI-resolution simulations. The line style indicates the collision kernel, with CTRL represented by a solid line and TURB by a dashed line. Where it appears that only a solid line exists for a given resolution, there is no noticeable difference between CTRL and TURB simulations. Vertical profiles of the observations binned in 5-m-altitude increments are plotted in black for those variables for which observations exist.

\section{Observations and case studies}

Observational data are derived from research flights conducted during the POST campaign, which took place during July and August 2008 in a box bounded by $35.5^{\circ}-37.5^{\circ} \mathrm{N}, 122.5^{\circ}-124.5^{\circ} \mathrm{W}$, off the coast of Monterey, California. Research flights were flown by the Center for Interdisciplinary Remotely Piloted Aircraft Studies (CIRPAS) Twin Otter, which was instrumented with thermodynamic, dynamic, and microphysics probes. Details of the instrumentation are available in Carman et al. (2012) and Gerber et al. (2013).

Of primary relevance to this study are the microphysics probes. Cloud drops of diameter $2-100 \mu \mathrm{m}$ are sampled by an Artium phase Doppler interferometer (PDI; Chuang et al. 2008), and drizzle drops of diameter $25-1550 \mu \mathrm{m}$ are sampled by a Droplet Measurement Technologies cloud imaging probe (CIP; Baumgardner and Korolev 1997; Korolev 2007). The sampling range of the PDI and CIP overlap, so construction of a merged DSD from the full size range sampled $(2-1550 \mu \mathrm{m})$ for comparison with model output involves selection of a crossover size between instruments. The full sampling range of one instrument could be used, but the CIP has known sizing issues for drops smaller than $100 \mu \mathrm{m}$ (e.g., Strapp et al. 2001); hence, it is desirable to minimize use of CIP bins smaller than $100 \mu \mathrm{m}$. While the PDI has no such sizing issues, its small sampling volume results in degradation of population statistics for drops significantly larger than $\sim 80 \mu \mathrm{m}$ in the relatively clean conditions observed during POST (12 of 17 flights had mean drop concentration $\bar{N} \lesssim 100 \mathrm{~cm}^{-3}$; Witte et al. 2017). The crossover diameter is chosen to be $65 \mu \mathrm{m}$, such that there is almost no overlap between the two instruments. While this choice leads to the use of two CIP bins sampling drops $d<100 \mu \mathrm{m}$, we found this produced the best full DSD.

All observed microphysical quantities, except liquid water content (LWC) and drop concentration $N$, are calculated from $1-\mathrm{Hz}$ merged DSDs, and profiles are derived by taking medians over 5 -m-altitude bins. Profiles of LWC and $N$ were calculated from only the PDI (Carman et al. 2012) because cloud base height is estimated using cloud LWC and should not take into account contributions to liquid water from sedimenting drizzle drops (in this case, defined as drops in the CIP range, i.e., $d>65 \mu \mathrm{m}$ ).

Flights during POST focused on the cloud-top region and the inversion layer above it. The Twin Otter primarily sampled an altitude range within $\sim 100 \mathrm{~m}$ of cloud top by performing 30 -min $(\sim 100 \mathrm{~km})$ sawtooth maneuvers at an ascent/descent rate of $1.5 \mathrm{~m} \mathrm{~s}^{-1}$ across a quasiLagrangian trajectory, with a full boundary layer slant profile and a series of three short $(22 \mathrm{~km})$ level legs from near the sea surface to midcloud preceding each sawtooth leg. Further information on POST flight patterns can be found in Gerber et al. (2013). This focus on a thin layer of the atmosphere resulted in limited sampling of the surface mixed layer, the cloud base, and the free troposphere. As such, several of the free-tropospheric soundings are based on only two to four aircraft traverses. Initial soundings are constructed from idealized linear piecewise fits to the observations to reflect low confidence in the ability of a few data points to represent the mean state of the atmosphere.

The criteria for case study selection were a welldeveloped cloud layer (no incipient/dissipating cloud), minimal change in boundary layer height over the observational period (absolute change in inversion height $\left|d z_{i} / d t\right|<1 \mathrm{~cm} \mathrm{~s}^{-1}$ ), and minimal wind shear $\left(U_{s}<0.15 \mathrm{~s}^{-1}\right)$. The cases selected are TO14 (12 Aug 2008) and TO17 (15 Aug 2008), which were specifically chosen to contrast nocturnal, drizzling conditions (TO14) with daytime, nonprecipitating conditions (TO17). Flight TO7, a daytime precipitating case, also met these criteria. Table 1 gives values of prescribed parameters used for each simulation. The surface sensible and latent heat fluxes are computed from aircraft observations during level near-sea-surface flight legs $(z \sim 25-30 \mathrm{~m}$ above sea level; D. Khelif 2016, personal communication), and SST (necessary for radiation calculations) is taken from buoy observations (NDBC $46042 ; 36.785^{\circ} \mathrm{N}, 122.398^{\circ} \mathrm{W}$ ) at the nearest time to aircraft takeoff. Aerosol number mixing ratio $N_{a}$ was set to match the average observed cloud drop number concentration within cloud (defined as LWC $>0.01 \mathrm{~g} \mathrm{~m}^{-3}$ ). The observational context of 

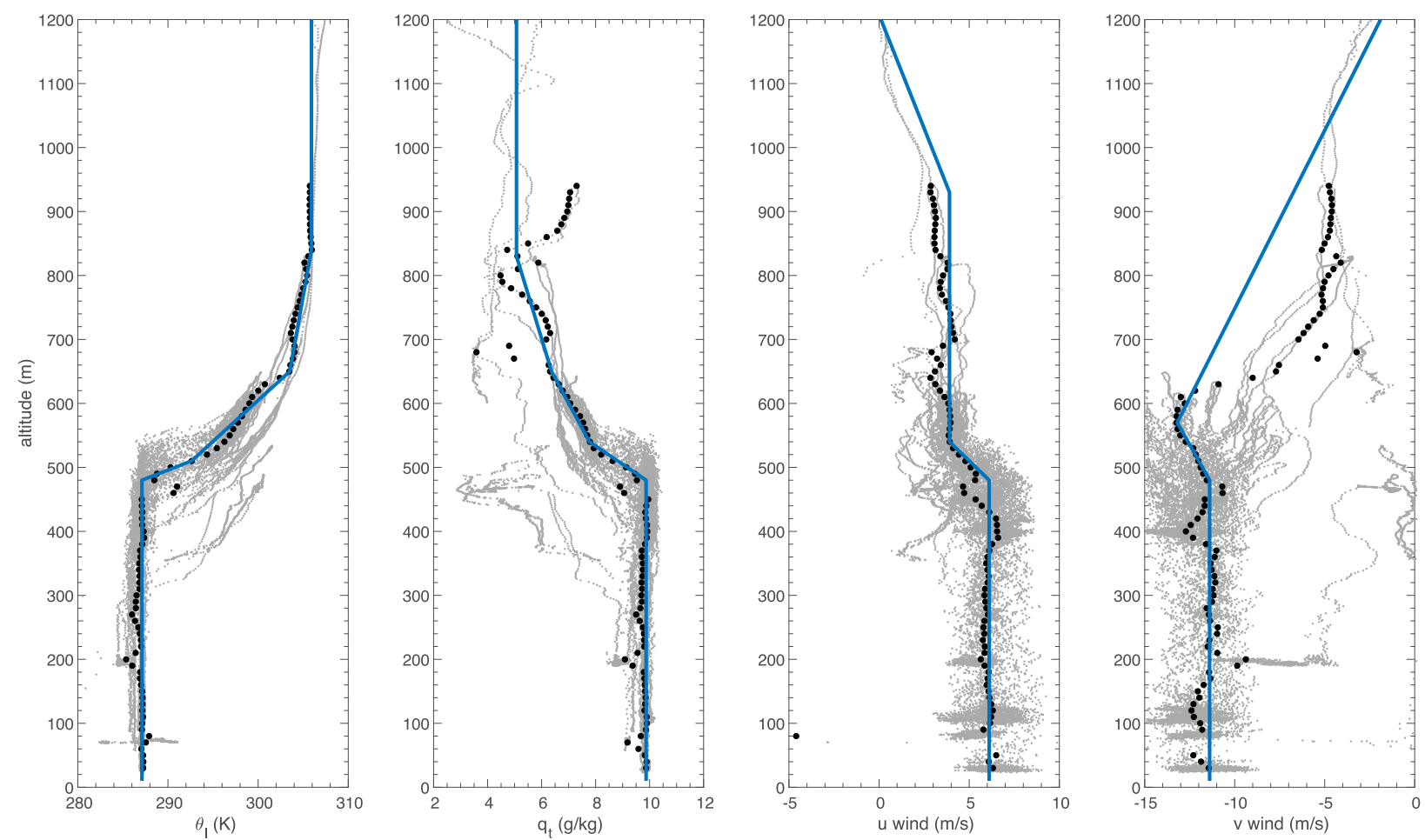

FIG. 1. Input soundings for TO14. (from left to right) Profiles of liquid water potential temperature $\theta_{l}$, total water mixing ratio $q_{t}, u$-wind component (west-east), and $v$-wind component (north-south). Gray dots are 1-Hz observations, black-filled circles are 10-m binned median observations, and blue solid lines are initial model soundings.

each case will be explored individually in the remainder of this section.

\section{a. Case 1: TO14}

Figure 1 shows the model initial soundings superimposed on Twin Otter (TO) observations. TO14 sampled a nocturnal marine stratocumulus setting with a moderate inversion capping the boundary layer starting at $490 \mathrm{~m}\left(\Delta T=11.7 \mathrm{~K}, \Delta q_{v}=-1.47 \mathrm{~g} \mathrm{~kg}^{-1}\right.$; Gerber et al. 2013). Despite a change in wind direction $\left(9^{\circ}\right)$ and magnitude $\left(6.2 \mathrm{~m} \mathrm{~s}^{-1}\right)$ through the inversion, there was minimal shear at cloud top $\left(U_{s}=0.069 \mathrm{~s}^{-1}\right)$. Increasing the complexity of the $v$-wind component sounding by including the rapid decrease in wind speed from 600 to $700 \mathrm{~m}$ did not substantially alter simulation results. The 0000 UTC upper-air sounding from Oakland Airport $(\mathrm{OAK})$ is used in conjunction with a standard summer subtropical sounding (McClatchy et al. 1971) to inform the model radiation parameterization. The OAK sounding broadly agrees with the aircraft measurements (up to $1 \mathrm{~km}$ ). Above that, temperature decreases with altitude until $16 \mathrm{~km}$, and $q_{t}$ decreases monotonically (not shown).

The profile of the merged DSD is presented in Fig. 2. Mode diameter increases from $12 \mu \mathrm{m}$ at cloud base to $\sim 27 \mu \mathrm{m}$ at cloud top. Interestingly, DSD width as measured by standard deviation $\sigma$ of drop diameter is a constant $\sim 4 \mu \mathrm{m}$ throughout the cloud layer, resulting in decreasing relative dispersion $[\sigma(d) / \bar{d}]$ with altitude (not shown). Note that $\sigma$ and relative dispersion are expressed in terms of diameter instead of radius. This value of standard deviation is comparable to previously observed values (e.g., Pawlowska et al. 2006; Lu et al. 2007), although we observe considerably lower $\sigma$ than that measured by Hudson and Svensson (1995) in comparable drop concentration conditions (likely due to differences in instrumentation). The decrease of relative dispersion with altitude is consistent with the low drop number concentration marine case presented by Pawlowska et al. (2006). Drizzle drops $(d>100 \mu \mathrm{m})$ were observed at all levels, with significant concentrations of drizzle drops $d>200 \mu \mathrm{m}$ in the lowest $100 \mathrm{~m}$ of cloud and the largest drops approaching $1 \mathrm{~mm}$ in diameter. At lower levels, a shoulder in the DSD at $d \sim 180 \mu \mathrm{m}$ can be seen. TO14 was the most heavily precipitating case observed during POST, with mean cloud base rain rate $R_{\mathrm{CB}}=0.5 \mathrm{~mm} \mathrm{day}^{-1}$ and cloud layer $N \approx 78 \mathrm{~cm}^{-3}$. Apparent gaps in the DSD between 50 and $80 \mu \mathrm{m}$ are a consequence of the choice of crossover diameter between the PDI and CIP. 


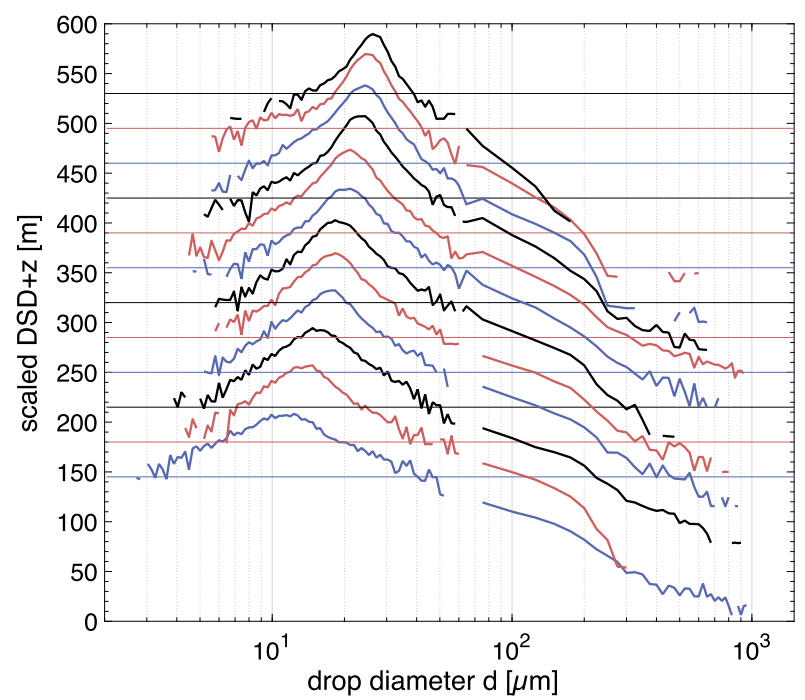

FIG. 2. TO14 profile of the merged DSD as a function of altitude in 5-m-altitude bins (shown every $35 \mathrm{~m}$ ). The units of the vertical axis are the logarithm of concentration translated by altitude and scaled such that three ticks on the vertical axis correspond to one order of magnitude in concentration $d N / d \log d$ [i.e., the plotted quantity is $\left.30 \log _{10}(d N / d \log d)+z\right]$. The alternating colors are solely for visual clarity, and the thin horizontal lines show the altitude associated with each DSD.

\section{b. Case 2: TO17}

TO17 is one of the more complex POST cases, with a polluted haze layer (aerosol concentration $\sim 1400 \mathrm{~cm}^{-3}$ ) occupying the first $200 \mathrm{~m}$ above the inversion and cirrus above that $\left(z_{\mathrm{CT}}>8 \mathrm{~km}\right)$. The inversion itself was well defined in terms of temperature but exhibited a weakly positive moisture jump (Fig. $3 ; \Delta T=6.8 \mathrm{~K}$, $\Delta q_{v}=+0.21 \mathrm{~g} \mathrm{~kg}^{-1}$; Gerber et al. 2013). Despite the prevailing onshore winds (i.e., $u>0$ ) during TO17, we speculate that the haze layer was likely of continental origin. The haze appeared to impinge on cloud top, but did not contribute significantly to $\mathrm{CCN}$, which occurred in abundances less than $65 \mathrm{mg}^{-1}$ at $0.1 \%$ supersaturation in the free troposphere. Cloud drop concentration averaged $80 \mathrm{~cm}^{-3}$, though higher values exceeding $200 \mathrm{~cm}^{-3}$ were observed farther offshore, some of the highest concentrations seen during POST. Although $R_{\mathrm{CB}}$ was negligible during this flight, isolated values in excess of $1 \mathrm{~mm}$ day $^{-1}$ were observed.

The profile of the merged DSD is given in Fig. 4 and shows a clearly nonprecipitating cloud layer with very few drops $d>100 \mu \mathrm{m}$ observed. Decreasing relative dispersion with altitude and the lack of a shoulder in the DSD (as seen in TO14) support this interpretation. TO17 displays much less drizzle despite having comparable $N$ to TO14, which can be attributed to the cloud layer being $80-90 \mathrm{~m}$ shallower during TO17.
Limited concentrations of larger drops were observed, but it should be noted that drops of the mode size are separated by about eight orders of magnitude in concentration from the largest drops observed at the same level. The increased small drop concentrations $(d<10 \mu \mathrm{m})$ apparent near $300 \mathrm{~m}$ in Fig. 4 coincide with aircraft passes through a ship track. Finally, there is no evidence of activation near cloud top, consistent with the assertion that the overlying haze layer contained few $\mathrm{CCN}$.

\section{Model results and comparison with observations}

We begin our analysis of the results with basic thermodynamic and bulk microphysical variables to demonstrate that the LES reasonably reproduces the case studies. In section 5, we compare simulated and observed DSDs to better understand discrepancies in bulk quantities between simulations and observations as well as differences among model microphysical configurations. Vertical profiles from LES output are horizontal means averaged over hours 3-6 unless otherwise noted. Observational profiles are calculated by taking medians over flight data in 5-m-altitude bins to agree with model vertical resolution in the boundary layer. In all figures, blue shading indicates LO bin resolution and red $\mathrm{HI}$ bin resolution, solid lines the quiescent collision kernel (CTRL), and dashed lines the turbulent kernel (TURB).

\section{a. Case 1: TO14}

\section{1) Domain AVerage TIMe Series}

Simulations of TO14 exhibit liquid water path (LWP) and cloud boundaries in good agreement with observational constraints, as shown in Fig. 5. Model LWP starts higher than observed and ends with LWP within $5 \%$ of the upper observational bound. The beginning of the decrease in LWP from its peak is roughly coincident with surface precipitation rate, reaching a maximum just before $3 \mathrm{~h}$ for each model configuration, and both LWP and surface precipitation rate reach an approximate steady state by the final hour of the simulations. LWP is primarily being reduced by precipitation as opposed to entrainment, which after $2 \mathrm{~h}$ is typically lower than the average observed value, $E_{\mathrm{obs}}=0.92 \pm 0.18 \mathrm{~cm} \mathrm{~s}^{-1}$ [dashed line; bottom panel, Fig. 5; value from Gerber et al. (2013)].

\section{2) Profiles}

Profiles of LES output and aircraft measurements for TO14 are shown in Fig. 6. The inversion is $35-40 \mathrm{~m}$ higher than observed. Total moisture $q_{t}=q_{v}+q_{c}$ is lower than observed by $0.3-0.4 \mathrm{~g} \mathrm{~kg}^{-1}$ between 380 and $500 \mathrm{~m}$, but agrees well with the initial profile and aircraft 

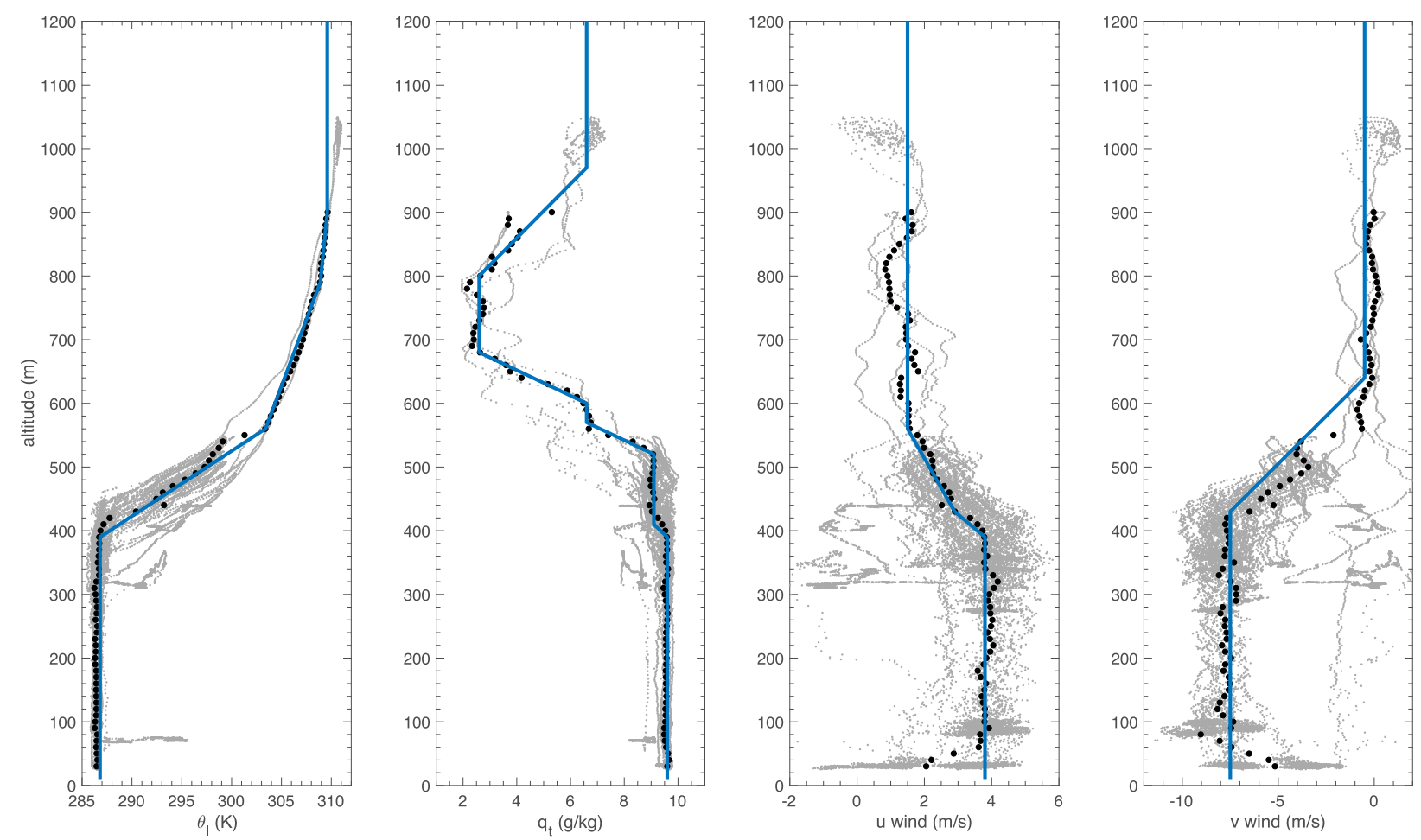

FIG. 3. Input soundings for TO17. (from left to right) Profiles of liquid water potential temperature $\theta_{l}$, total water mixing ratio $q_{t}, u$-wind component (west-east), and $v$-wind component (north-south). Gray dots are all observations, black filled circles are 10-m binned median observations, and blue solid lines are initial model soundings.

measurements above $550 \mathrm{~m}$. The temporally averaged model profiles presented mask evolution of the boundary layer (BL): in addition to deepening by $\sim 60 \mathrm{~m}$ total, the BL cools by $0.4 \mathrm{~K}$ and dries by $0.3 \mathrm{~g} \mathrm{~kg}^{-1}$. Model configuration does not have a significant effect on these profiles or their temporal evolution.

The agreement (or lack thereof) between model and observations in the thermodynamic profiles is reflected in the bulk microphysical variables as well: as can be seen in Fig. 5, cloud top is higher than observed since the inversion is higher, although peak LWC is the same magnitude $\left(\sim 0.7 \mathrm{~g} \mathrm{~m}^{-3}\right)$ and at the same altitude $(\sim 450 \mathrm{~m})$ as observed. Number concentration $N$ is somewhat of a tunable parameter since $N_{a}$ is prescribed, and good agreement with observed cloud mean $N=79 \mathrm{~cm}^{-3}$ is found for $N_{a}=125 \mathrm{mg}^{-1}$. Despite all model configurations for this case having identical inputs and prescribed parameters (e.g., $N_{a}$ ), the HI- and LO-resolution configurations have noticeably (if subtly) different $N$ and LWC profiles. The turbulent collisioncoalescence kernel has barely any effect on the bulk microphysical variables, which can be attributed to the low turbulence dissipation rate $\varepsilon$ above the surface shear layer. While it is infeasible to generate an observed profile of $\varepsilon$ due to the aircraft sampling pattern,
Jen-La Plante et al. (2016) estimate $\varepsilon \sim 6 \mathrm{~cm}^{2} \mathrm{~s}^{-3}$ from aircraft observations in the well-mixed cloud-top layer for TO14, suggesting that the LES is generating realistic turbulence magnitude.

Finally, simulated sedimentation flux $R$ (in units of rain rate; $\mathrm{mm} \mathrm{day}^{-1}$ ) shows variable agreement with the observations. Note that the subcloud $R$ profile shown in Fig. 6 was also computed for $R>0$ (+ symbols). This was done to minimize the effects of intermittency, which otherwise result in median $R(z)=0$ for $z<80 \mathrm{~m}$, where the aircraft observed no precipitation about $60 \%$ of the time with no obvious spatial dependence. This alternate subcloud profile gives the typical magnitude of $R$ when it is drizzling. A comparable alternate profile is not constructed from model output, as the precipitation fraction (number of model columns with surface precipitation) was above $75 \%$ for the entirety of the sampling period for all simulations. Descending from cloud top, simulated $R$ is lower than observed, within the range of observed values near midcloud for all configurations, and comparable or greater than the upper observed bound from cloud base to the surface. For the HI configurations, $R$ noticeably exceeds the observed median values of $\sim 0.5 \mathrm{~mm} \mathrm{day}^{-1}$ in the lowest $100 \mathrm{~m}$, a curious result given the minor differences between $\mathrm{HI}$ and $\mathrm{LO}$ in 


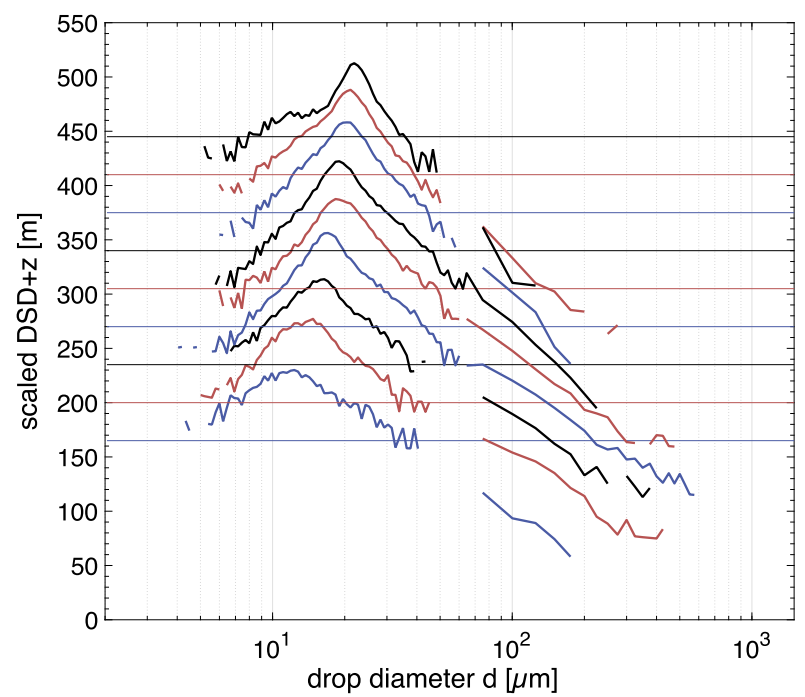

FIG. 4. TO17 profile of the merged DSD as a function of altitude in $5 \mathrm{~m}$ altitude bins (shown every $35 \mathrm{~m}$ ). The units of the vertical axis are the logarithm of concentration translated by altitude and scaled such that three ticks on the vertical axis correspond to one order of magnitude in concentration $d N / d \log d$ [i.e., the plotted quantity is $\left.30 \log _{10}(d N / d \log d)+z\right]$. The alternating colors are solely for visual clarity and the thin horizontal lines show the altitude associated with each DSD.

$N\left(<2 \mathrm{~cm}^{-3}\right)$ and LWC $\left(<0.01 \mathrm{~g} \mathrm{~m}^{-3}\right)$. The response of the turbulent kernel as a function of bin resolution is configuration dependent: for HI resolution, coupling turbulence to collision-coalescence produces a very small effect on $R$ relative to the CTRL kernel that peaks in the midcloud region, while for LO resolution, turbulence increases $R$ more substantially (by $\sim 0.1 \mathrm{~mm} \mathrm{day}^{-1}$ ) in the lower portion of the cloud.

\section{b. Case 2: TO17}

\section{DOMAIN AVERAGE TIME SERIES}

TO17 LWP is consistently near the lower observational bound of $68 \mathrm{~g} \mathrm{~m}^{-2}$, except during spinup (Fig. 7). All configurations follow nearly the same trajectory in terms of LWP, with only very small differences in terms of surface accumulation (note vertical axes of the third panel of Fig. 7). Given that the entrainment rate is reasonably close to observed $\left(E \sim 0.25 \mathrm{~cm} \mathrm{~s}^{-1}\right)$ and precipitation is negligible, it is somewhat surprising that cloud top does not rise over the course of the simulations. Reducing the prescribed large-scale divergence by a factor of 2 did not affect this result.

\section{c. Profiles}

The profiles of $\theta_{l}$ and $q_{t}$ in Fig. 8 show a lower inversion height than observed (by 20-30 m) and slight warming and moistening of the $\mathrm{BL}$ (by about $1 / 10 \mathrm{~K}$ and $\mathrm{g} \mathrm{kg}^{-1}$, respectively). Cloud top is accordingly lower; although $N$ agrees fairly well with the observations in terms of magnitude (observed cloud mean $N \sim 80 \mathrm{~cm}^{-3}$ ), the shallower cloud layer is unable to reach the same peak LWC, falling short by $\sim 0.05 \mathrm{~g} \mathrm{~m}^{-3}$. It is unclear what causes the lowering of the cloud layer, although it may be related to drop sedimentation; a simulation with sedimentation deactivated resulted in an LWC profile that matched cloud-top altitude and peak LWC to within 5\% of the observed values (not shown). Alternatively, the overlying haze layer may decrease cloud-top evaporation due to decreased incident shortwave radiation. The relatively high moisture content of the haze layer (recall there was almost no moisture jump observed during TO17) may also have limited the ability of the cloud layer to cool via outgoing longwave radiation, dampening the dynamics of the boundary layer. Inclusion of the radiative effects of the haze layer in the model configuration would likely improve agreement with the observations.

Differences in $N$ and LWC between LO- and HI-binresolution simulations are again minor for $N$ and LWC, and the turbulent kernel has no discernible effect, with mean $\varepsilon$ very near the limit at which the kernel is activated (threshold $\varepsilon=1 \mathrm{~cm}^{2} \mathrm{~s}^{-3}$ ) above $200 \mathrm{~m}$. Despite the similarity of $N$ and LWC for LO and HI configurations, peak $R$ is $\sim 0.13 \mathrm{~mm}$ day $^{-1}$ higher in the $\mathrm{HI}$ configuration, a value still $0.2 \mathrm{~mm} \mathrm{day}^{-1}$ lower than peak observed $R$. The discrepancy with respect to observations is likely due to the reduced depth of the simulated cloud deck. As with Fig. 6, the subcloud $R$ profile was also computed for $R>0$ only ( + symbols); this is not as informative for TO17 as for TO14, where only $12 \%$ of observations below $100 \mathrm{~m}$ had $R>0$, and a median value of $R=0$ is likely more representative.

\section{Comparison of LES DSD output with observations}

From Figs. 6 and 8, it is clear that the microphysics scheme can reproduce observed bulk DSD properties such as $N$ and LWC with fidelity to the extent that the input parameters and thermodynamic profiles upon which they depend are accurate, but the vertical profile of a higher-order moment of the DSD such as $R$ (depending on drop size, $R$ corresponds to the fourth or fifth moment of the DSD) is more problematic. These discrepancies occur despite minor differences in mean profiles of LWC and $N$ and therefore must be caused by differences in the shape of modeled and observed DSDs, which arise from a combination of uncertainty in process rates, simplified representation of the underlying microphysics, and differences in thermodynamic forcing. Directly untangling the contribution of 

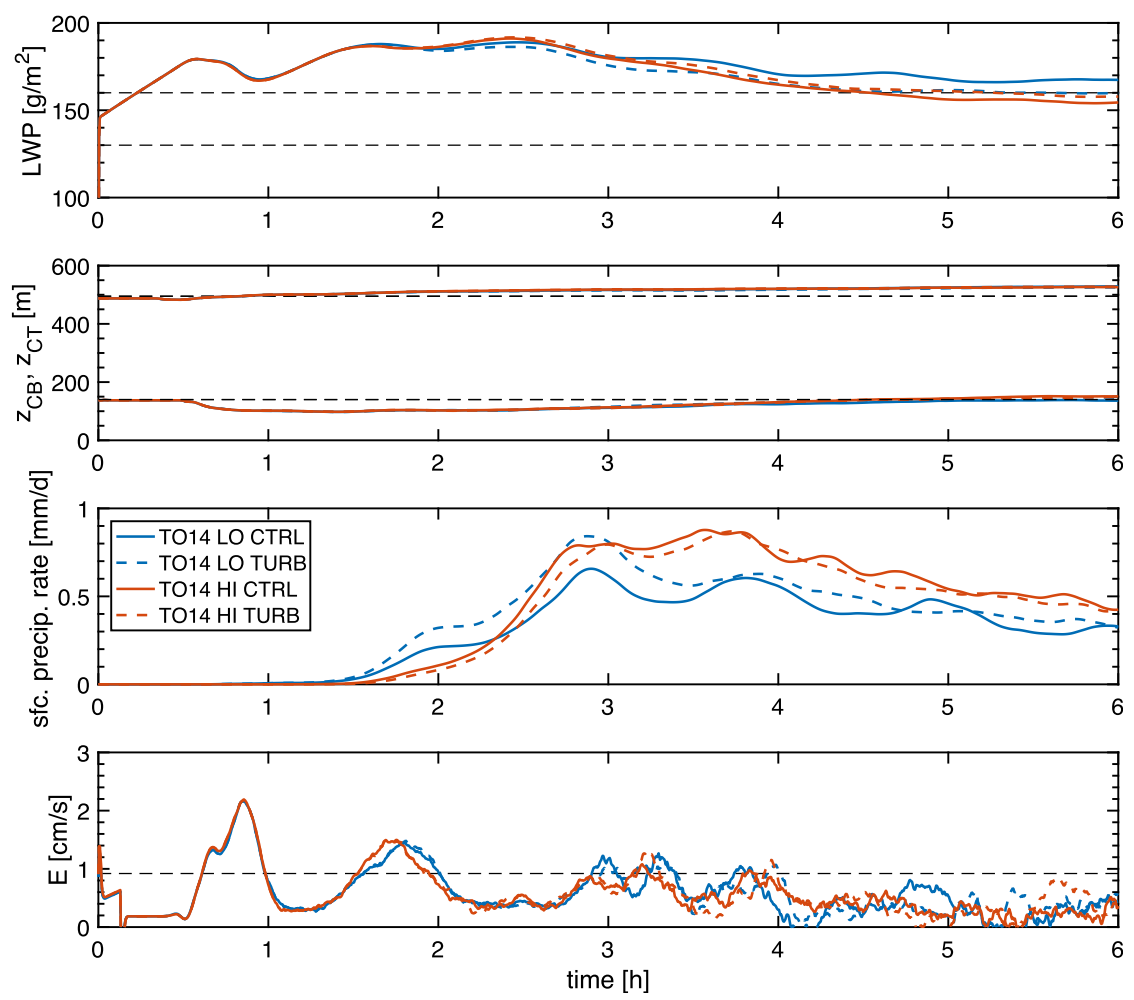

FIG. 5. Domain average time series, TO14 case, of LWP, cloud base and top altitude $\left(z_{\mathrm{CB}}\right.$ and $z_{\mathrm{CT}}$, respectively), surface precipitation accumulation rate, and entrainment rate. Dashed black lines indicate observational constraints. LWP bounds are computed from TO profile maneuvers through the entire cloud depth; the minimum and maximum observed values are shown. Cloud boundaries $z_{\mathrm{CB}}$ and $z_{\mathrm{CT}}$ are the lowest and highest levels with mean LWC $>0.01 \mathrm{~g} \mathrm{~m}^{-3}$ (same definition used for model output). Entrainment rate is calculated as $E=d z_{i} / d t+D z_{i}$ (Ackerman et al. 2009), where inversion height $z_{i}$ is defined as the height of the maximum $\theta_{l}$ gradient, and $D$ is subsidence rate.

process rate uncertainty and flawed physics based on aircraft observations is challenging (e.g., Witte et al. 2017), but model output makes this task more tractable because output DSD statistics are robust, and different processes can be selectively activated or deactivated within the microphysics scheme.

To quantify how well the model reproduces observed DSD shape, several metrics are utilized that collapse the DSD from a function of many size categories to a single value: standard deviation $\sigma$ of drop number size distribution (a standard measure of DSD width), various percentile diameters of drop mass size distribution (e.g., $\left.d_{50}, d_{99}\right)$, and $\Delta d_{99}=d_{99}-d_{50}$, which quantifies only the width of the right tail. These metrics allow for an easily interpreted analysis of DSD variation with altitude yet still depend on the shape of the full distribution. Model DSD metrics are calculated from 3D output of bin microphysics variables and observed metrics from $1-\mathrm{Hz}$ observations to avoid artificial broadening by calculating values from horizontal-mean DSDs.
Profiles of $\sigma$ and $\Delta d_{99}$ for both case studies are shown in Fig. 9. In addition to the basic configurations, two more curves showing output from simulations with only condensation/evaporation activated (LO COND and HI COND; dash-dot curves) are included. These two metrics give similar pictures of the model's performance but differ in the details: $\sigma$ and $\Delta d_{99}$ give a reasonable match to the observations away from cloud boundaries (for both cases, LO configurations are within the spread of observed $\sigma$ and HI within the spread of observed $\Delta d_{99}$ ) but diverge from the observations at cloud top and below cloud base. The COND simulations also agree well with observed $\sigma$ in the absence of collisioncoalescence for both cases, in general tracking within $0.5 \mu \mathrm{m}$ of the lower bound of observed $\sigma$ away from cloud boundaries. This might be expected for TO17 since it is essentially nonprecipitating, but it is rather surprising that it occurs for TO14 as well. In contrast with the good agreement in the central part of the cloud, $\sigma$ is too large near cloud top, which we attribute to the 

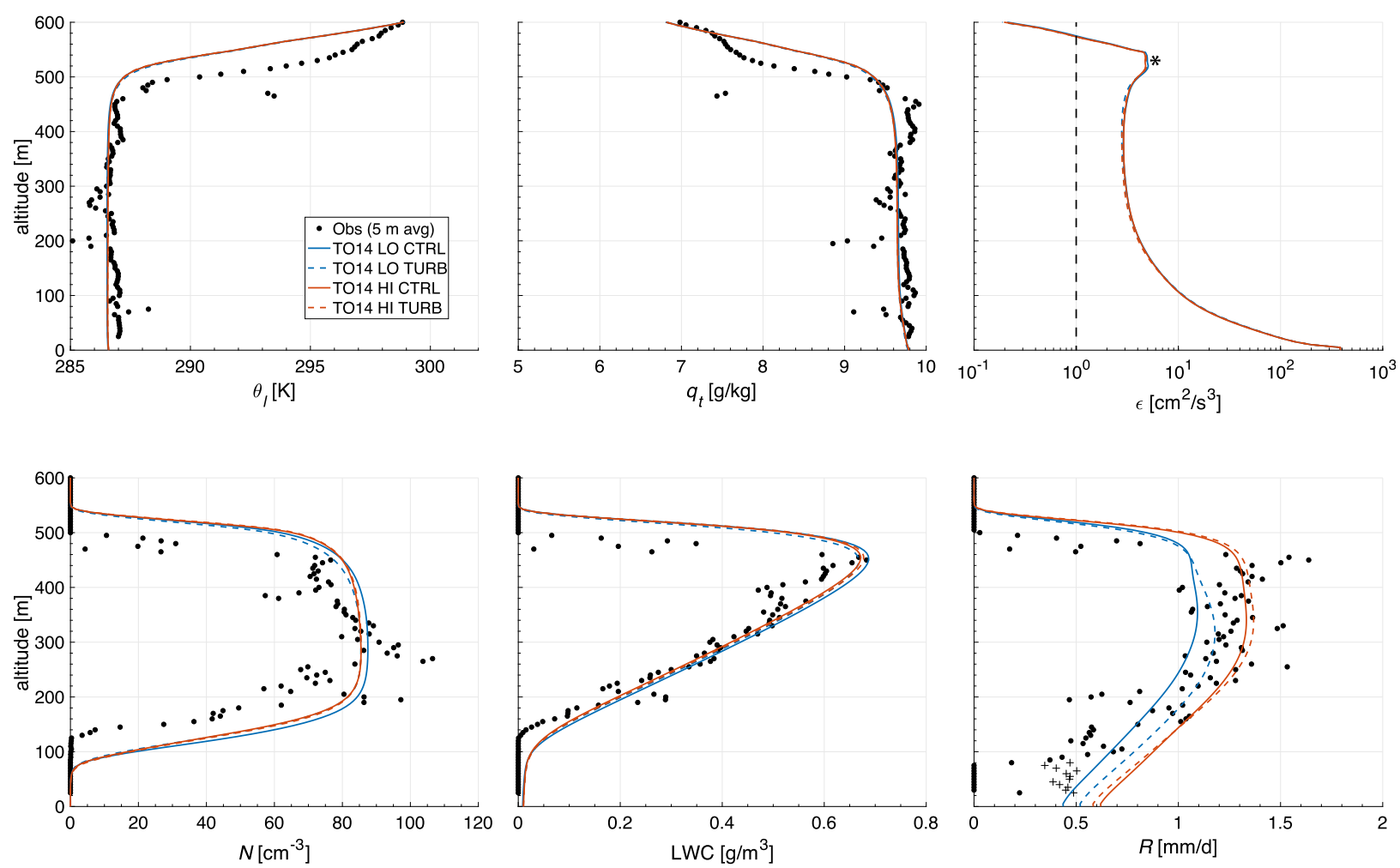

FIG. 6. Profiles of time and domain average LES output, TO14 case, of liquid water potential temperature $\theta_{l}$, total moisture mixing ratio $q_{t}$, turbulence dissipation rate $\varepsilon$, drop number concentration $N$, LWC, and sedimentation flux $R$. The black dashed line in the $\varepsilon$ panel denotes the threshold $\varepsilon$ below which the turbulent kernel is not applied, and the asterisk is estimated observed $\varepsilon$ for the cloud-top layer. In the $R$ panel, + symbols denote subcloud levels for which the median was computed for $R>0$ only.

well-documented "spurious supersaturation" issue (Stevens et al. 1996b; Grabowski and Morrison 2008). Below cloud base, $\sigma$ is greater than observed for TO14 but does not grow large enough for TO17. It is interesting that the maximum observed values below cloud are quite large, despite TO17 having a much lower cloud base rain rate (TO14 maximum $\sigma=37.9 \mu \mathrm{m}$, TO17 maximum $\sigma=32.8 \mu \mathrm{m}$ ). While $\sigma$ has frequently been used as the preferred metric for spectral width in the literature because of its importance in radiation parameterizations (Martin et al. 1994; Liu and Daum 2000; Pawlowska et al. 2006), these results indicate that incloud $\sigma$ may be a poor metric for precipitation formation, as there is little difference between the precipitating and nonprecipitating cases.

Right tail width $\Delta d_{99}$ more successfully differentiates between drizzling and nondrizzling conditions within cloud. Note that the abscissae of the $\Delta d_{99}$ panels of Fig. 9 are identical in range; descending from cloud top, TO17 $\Delta d_{99}$ increases slowly and observed values never exceed $100 \mu \mathrm{m}$, while for TO14 observed $\Delta d_{99}$ increases almost linearly within cloud, peaking at $160-170 \mu \mathrm{m}$ a few tens of meters above cloud base. Below cloud base, there are few to no small cloud drops, causing $d_{50}$ to increase dramatically (e.g., Fig. 10), and therefore $\Delta d_{99}$ quickly decreases. In general, the shapes of the profiles are well reproduced by the LES, but the profile maxima are overpredicted and occur too close to the surface. For both cases, HI resolution produces larger maximum $\Delta d_{99}$ than LO. Focusing on TO14, the response of $\Delta d_{99}$ to the turbulent kernel is opposite for the two different spectral resolutions, with a turbulence-induced increase in $\Delta d_{99}$ for LO resolution and a decrease for HI. It is unclear whether the differing response to the turbulent kernel as a function of bin resolution is a numerical consequence of differences in how kernel coefficients are calculated (see Tzivion et al. 1999), or if it is instead a consequence of the tendency of the HI configuration to produce wider DSDs from condensation (i.e., larger $\sigma$ ). In other words, if the primary effect of the turbulent kernel is to accelerate the production of the first efficient collector drops, the DSDs obtained from condensation with the HI configuration may be sufficiently broad to mask the effects of the turbulent kernel in the context of marine stratocumulus.

Since $\Delta d_{99}$ depends on $d_{99}$ and $d_{50}$, it is instructive to examine both to determine why simulated $\Delta d_{99}$ is 

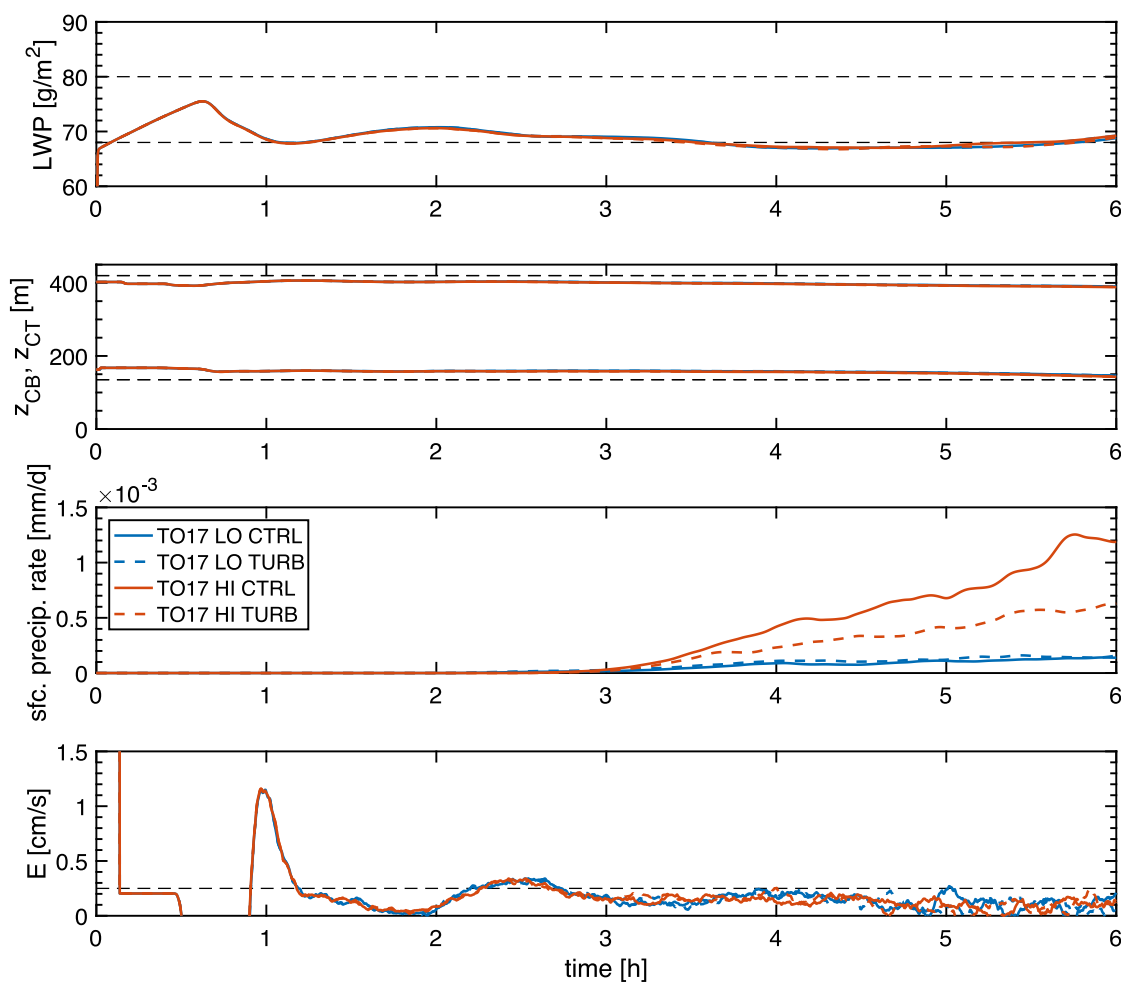

FIG. 7. Domain average time series, TO17 case, of LWP, $z_{\mathrm{CB}}$ and $z_{\mathrm{CT}}$, surface precipitation accumulation rate, and entrainment rate $E$. Dashed black lines indicate observational constraints. See Fig. 5 for more information.

typically larger than observed below cloud base. Profiles of various right tail percentile diameters $\left(d_{50}, d_{75}, d_{90}\right.$, $d_{95}$, and $\left.d_{99}\right)$ are presented in Figs. 10 and 11 . Beginning with case TO14 (Fig. 10), median diameter $d_{50}$ is best matched by the HI configurations, with the LO configurations $2-3 \mu \mathrm{m}$ smaller than observed in cloud. Moving to higher-percentile diameters, some disagreement with the observations is apparent, especially near and below cloud base. The altitude at which the model and observations diverge is successively higher in cloud, suggesting that the model microphysics does not create large drops as quickly as observed. At the extreme end of the right tail, though, simulated $d_{99}$ is comparable to observed (at least for the HI configuration) and continues to increase after observed $d_{99}$ ceases to grow near cloud base. With respect to $\Delta d_{99}$, it appears that the larger-than-observed values in Fig. 9 are due to overestimation of $d_{99}$, as opposed to $d_{50}$.

The median and intermediate percentiles of the right tail of the DSD for TO17 (Fig. 11) are comparable to TO14, agreeing well with the observations in cloud for the HI configurations. There is also some disagreement for $d_{75}$ through $d_{95}$ in the $100 \mathrm{~m}$ above cloud base, although it is not as pronounced for TO17. With $d_{99}$, on the other hand, a sudden shift in observed values to values greater than $50 \mu \mathrm{m}$ at $z \sim 250 \mathrm{~m}$ indicates that some drizzle drops were generated in cloud, which the model did not reproduce. We hesitate to ascribe any physical significance to this particular aspect of disagreement because it is unusual to observe a sharp increase in $d_{99}$ without a commensurate increase in other large percentiles (e.g., $\left.d_{90}, d_{95}\right)$.

\section{Discussion and implications}

Overall, LES with bin microphysics appears to reproduce the bulk microphysical quantities $N$, LWC, and $R$ with considerable fidelity in the context of drizzling and nondrizzling marine stratocumulus. This is particularly notable in the precipitating case, for which the simplifying assumption of constant $N_{a}$ is dubious: using Eq. (14) from Wood (2006), we estimate a cloud-mean coalescence scavenging rate of $18 \mathrm{~cm}^{-3} \mathrm{day}^{-1}$ from the TO14 LO CTRL simulation, or about $30 \%$ of observed mean $N$ for this case. Nevertheless, further questions are raised by the different results obtained using different numerical configurations of the microphysics scheme: Why does the response to activating the turbulent kernel vary as a function of bin resolution? 

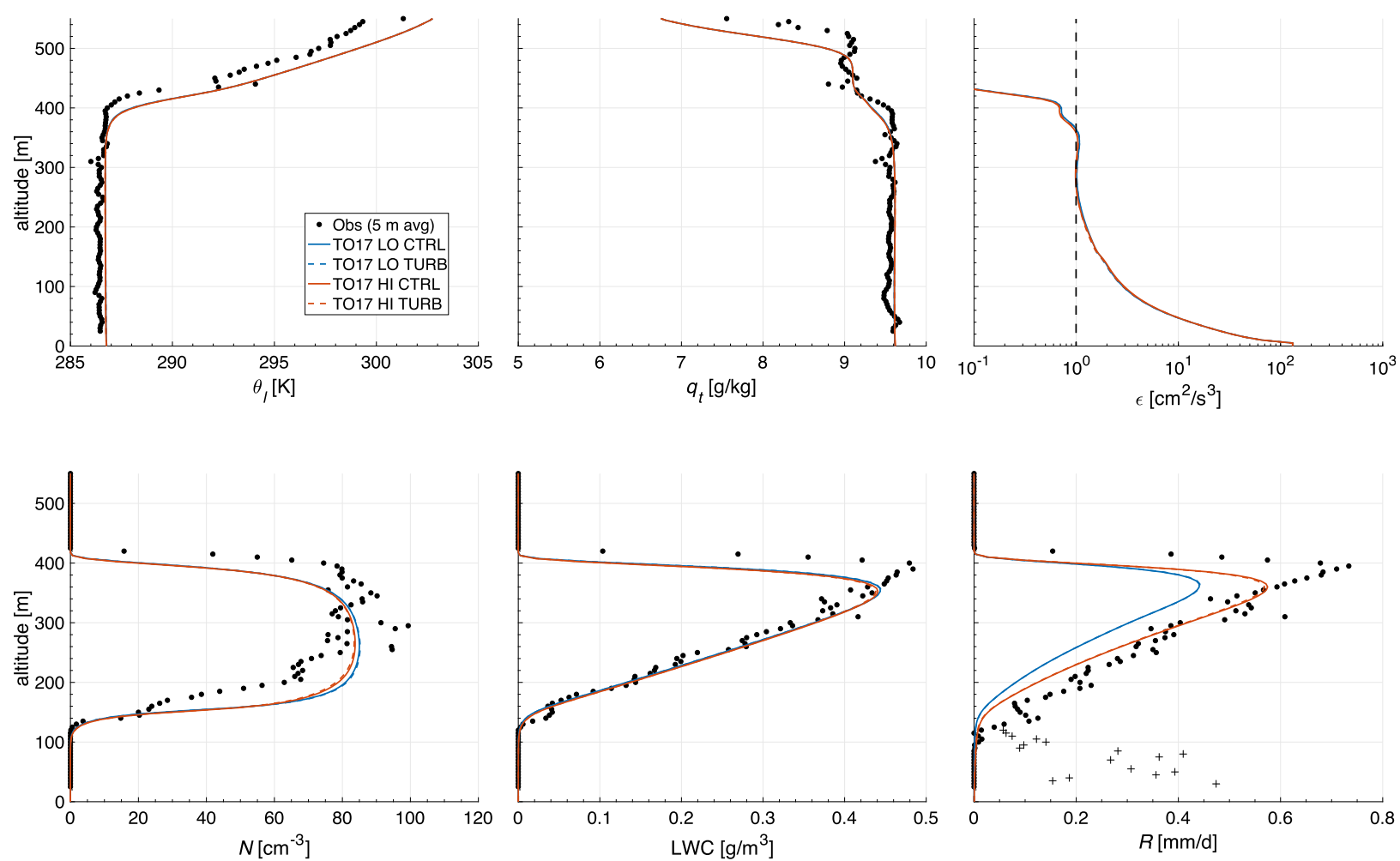

FIG. 8. Profiles of time and domain average LES output, TO17 case, of $\theta_{l}, q_{t}, \varepsilon, N$, LWC, and $R$. In the $R$ panel, + symbols denote subcloud levels for which the median was computed using $R>0$ only. See Fig. 6 caption for more information.

When the LES does adequately reproduce the profile of a higher-order moment such as $R$, is it for the "right" physical reasons?

Based on the argument of Morrison et al. (2018), we speculate that numerical diffusion caused by separating spatial advection and condensation/evaporation likely leads the model to produce spectra that are too wide (i.e., $\sigma$ greater than observed) regardless of spectral resolution. The issue is that vertical transport of drops by numerical mixing is not accompanied by changes in drop size (e.g., due to adiabatic lifting). This problem is worsened by the use of a coarse grid in the vertical. Using only condensation/evaporation in a 1D Eulerian model and 3D LES with the same microphysical scheme as that employed here, Morrison et al. (2018) found that increasing bin resolution leads to broader spectra, all else being equal. We obtain similar results in drizzling and nondrizzling conditions. Including the collisioncoalescence and sedimentation processes appears to exacerbate the issue: the HI configurations produce the widest spectra as measured by both $\sigma$ and $\Delta d_{99}$ (Fig. 9), as well as stronger subcloud sedimentation fluxes than the LO configurations. In addition, cloud base is $20-30 \mathrm{~m}$ too low in the drizzling case, which may be a signature of the spurious broadening problem in terms of evaporation. The link between DSD width from condensation/evaporation (best measured by $\sigma$ ) and from collision-coalescence (best measured by $\Delta d_{99}$ ) is surprisingly straightforward: in these simulations, the simulation with the largest $\sigma$ of the ensemble also had the largest $\Delta d_{99}$. Past work has typically focused on limiting numerical diffusion in the collision-coalescence scheme (e.g., Tzivion et al. 1999), but our results suggest that spurious broadening caused by condensation/ evaporation may propagate to collisional growth. This is not to say numerical diffusion in collision-coalescence schemes can be entirely ignored; at cloud base, the drizzle mode maximum (in terms of rain size distribution $d R / d \log d$; not shown) occurs at about the same size $(d \sim 200 \mu \mathrm{m})$ for both resolutions, but HI simulations have higher concentration at that size than LO as well as a truncated right tail (maximum size attained is about $100 \mu \mathrm{m}$ smaller for HI). In a future study, a method to limit this artificial DSD broadening will be implemented, and the question of why HI bin resolution produces wider spectra can be more rigorously addressed.

The tendency of TO14 HI simulations to produce wider spectra also has implications for understanding precipitation initiation in the framework of Eulerian 

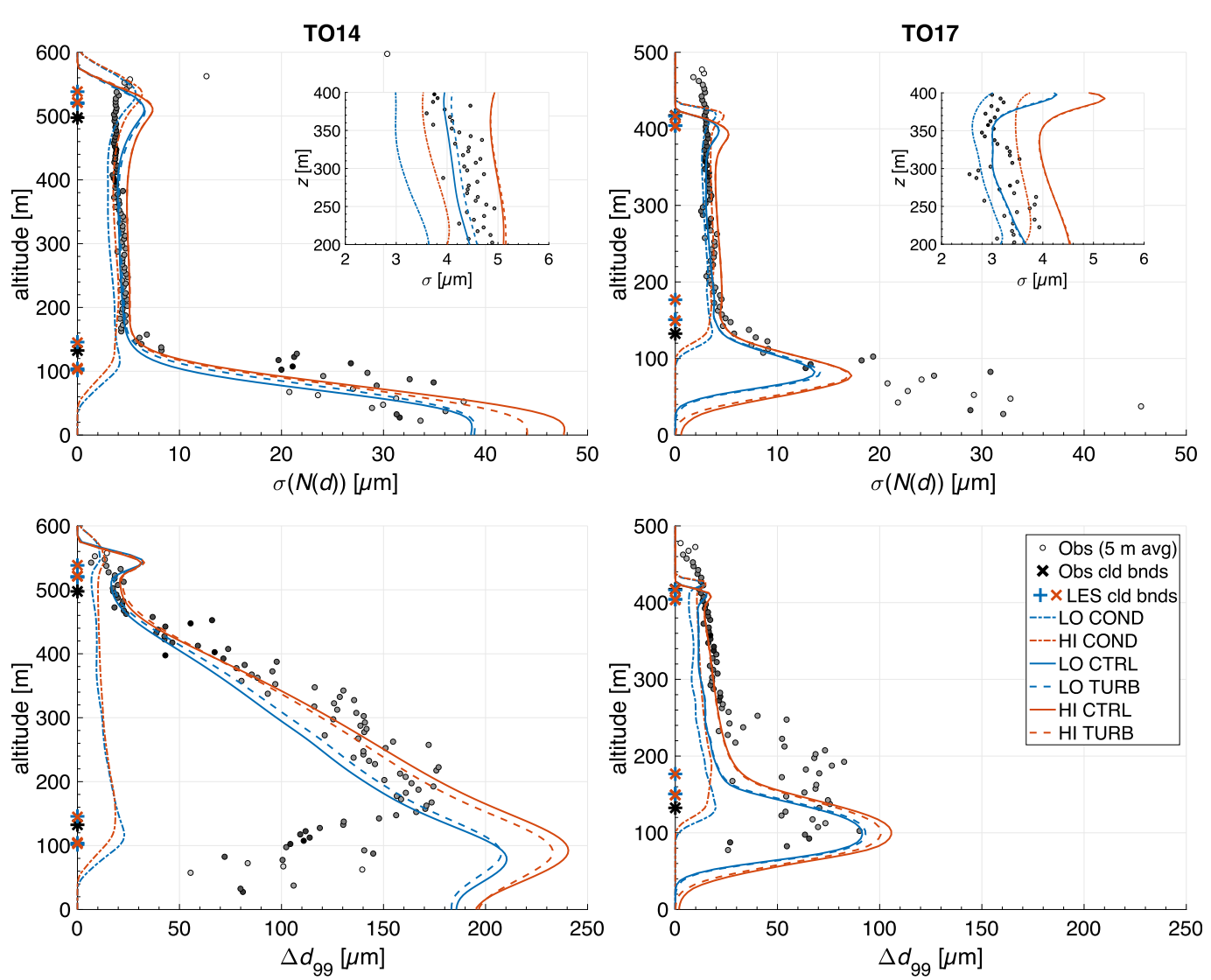

FIG. 9. Profiles of (top) $\sigma[N(d)]$ and (bottom) $\Delta d_{99}$. Results for (left) TO14 and (right) TO17. Insets of $\sigma$ panels show in-cloud values. Shading of the observations corresponds with observational density; darker shading indicates a relatively greater number of observations, and thus higher confidence in the plotted value. Cloud boundaries (symbols on ordinate axis) are the lowest and highest levels with $\mathrm{LWC}>0.01 \mathrm{~g} \mathrm{~m}^{-3}$ and $N>1 \mathrm{~cm}^{-3}$.

LES with bin microphysics. The bin scheme produces good agreement with observed $R$ [peak $R$ is near the right altitude for both cases and is of comparable magnitude for TO14, where HI $\max (R) \sim 1.3 \mathrm{~mm} \mathrm{day}^{-1}$ and observed $\max (R) \sim 1.6 \mathrm{~mm}$ day $^{-1}$ ] —even the shapes of the DSDs match reasonably well for both cases-and there is little to no evidence of a process rate bottleneck that prevents the model from forming sufficient drizzle. But if the reason for this good agreement is numerical as opposed to physical, then hypotheses regarding the physics (i.e., the roles of turbulent collision-coalescence, giant $\mathrm{CCN}$, entrainment broadening, etc. in warm rain formation) cannot be tested. This is especially true in weakly dynamically forced environments such as those simulated for this study and may help explain the divergent effects of the turbulent collision-coalescence kernel as a function of bin resolution. In the presence of weak turbulence, broader DSDs (i.e., HI CTRL) are associated with greater net collision-coalescence rates than narrower DSDs to which the turbulent kernel has been applied (LO TURB). Therefore, the turbulent kernel serves to broaden the distribution and increase $R$ for the LO TURB configuration relative to LO CTRL, while the DSD is already sufficiently broad for HI TURB that the primary effect of the kernel is to reduce the residence time of the very largest drops because they grow more quickly and sediment out faster.

\section{Conclusions}

Simulations of two case studies of marine stratocumulus with varying spectral resolution and collisioncoalescence numerics have been presented to evaluate the ability of LES with bin microphysics to reproduce in situ observed drop size distributions. The case studies were chosen to be relatively steady in terms of boundary layer characteristics and to contrast precipitating and nonprecipitating conditions. To the extent that the thermodynamic profiles (i.e., $\theta_{l}$ and $q_{t}$ ) are reproduced with fidelity, the model satisfactorily simulates bulk cloud properties such as LWP (Figs. 5 and 7), N, LWC, and $R$ (Figs. 6 and 8 ) with respect to the observations. 

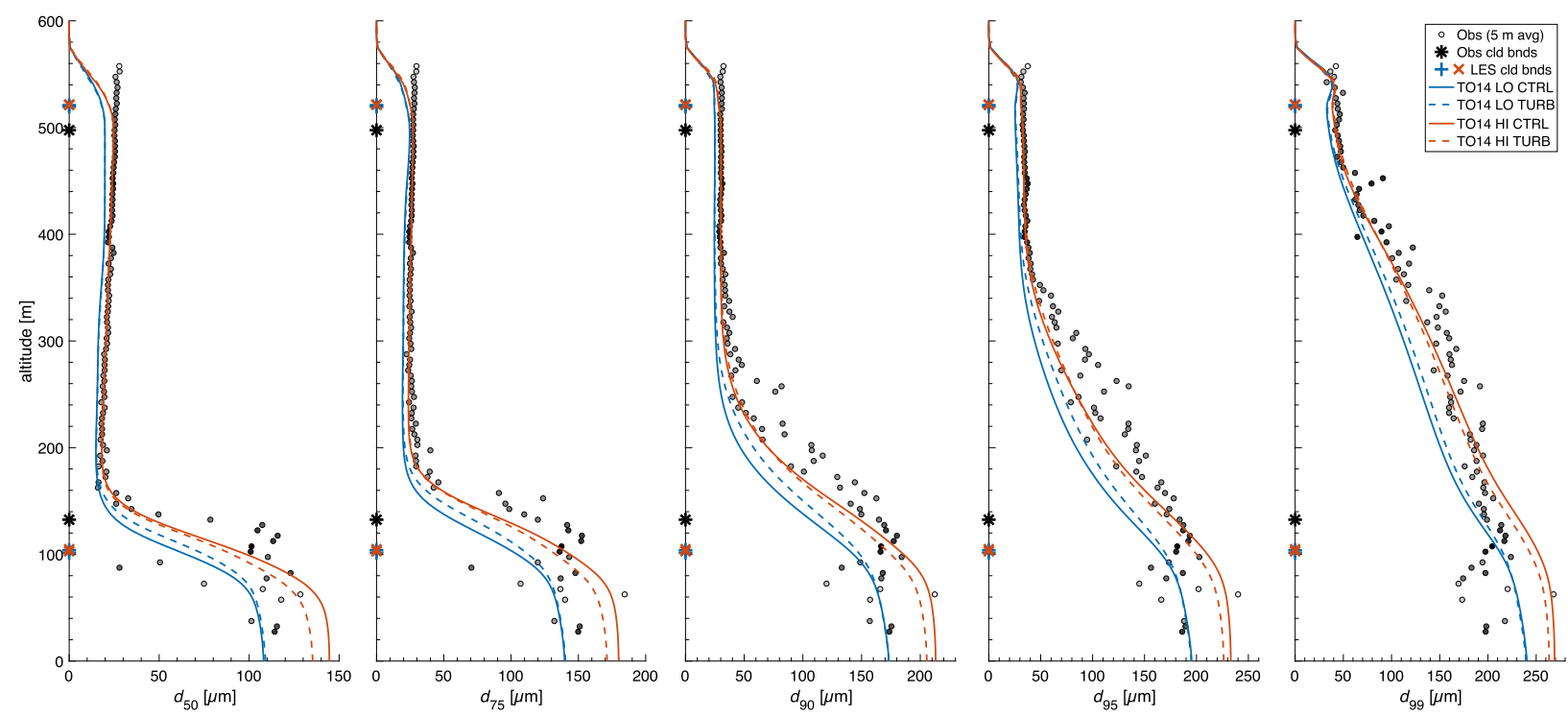

FIG. 10. Profiles of percentile diameters $d_{50}, d_{75}, d_{90}, d_{95}$, and $d_{99}$ for case TO14. Shading of the observations is as in Fig. 9. Cloud boundaries (symbols on the ordinate) are the lowest and highest levels with $\mathrm{LWC}>0.01 \mathrm{~g} \mathrm{~m}^{-3}$.

Nevertheless, there remain discrepancies between modeled and observed microphysical quantities near cloud boundaries; some of these are well understood (e.g., spurious supersaturation at cloud top), and others are less so (why are DSDs too wide below cloud base?). As with past studies (e.g., Khairoutdinov and Kogan 1999; Rémillard et al. 2017), we find too many of the largest drops, although in the case studies presented here, this primarily occurs near and below cloud base (Figs. 9 and 10). We suspect that the tendency of the model to produce overly broad DSDs is caused by separation of spatial advection and drop growth, but this hypothesis cannot be tested until a solution to the problem of combined Eulerian advection and condensation in bin schemes has been implemented.

Turbulent enhancement of collision-coalescence plays a relatively minor role in determining bulk microphysical profiles in the context of these simulations. Despite the low dissipation rates (typical in-cloud $\varepsilon<10 \mathrm{~cm}^{2} \mathrm{~s}^{-3}$ ), there are clear differences in $R$ and DSD shape between
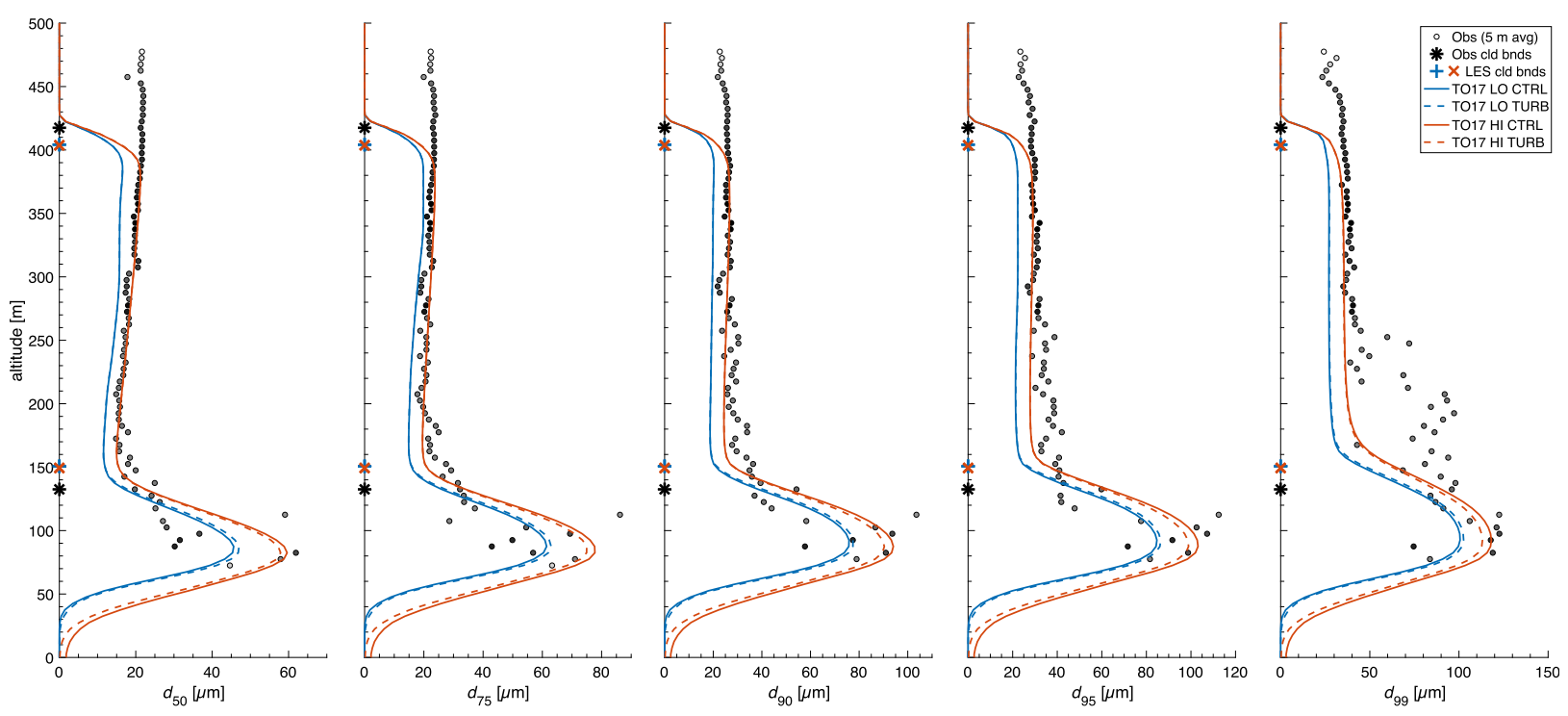

FIG. 11. Profiles of percentile diameters $d_{50}, d_{75}, d_{90}, d_{95}$, and $d_{99}$ for case TO17. Shading of the observations is as in Fig. 9. Cloud boundaries (symbols on the ordinate) are the lowest and highest levels with $\mathrm{LWC}>0.01 \mathrm{~g} \mathrm{~m}^{-3}$. 
the CTRL and TURB configurations for TO14 (Figs. 6, 9 , and 10), and we reiterate that numerical diffusion due to the handling of condensation in an Eulerian dynamical framework may limit the impact of the turbulent kernel on precipitation initiation, especially for $\mathrm{HI}$ bin resolution. Given that $\varepsilon$ is one to two orders of magnitude smaller than in shallow cumulus, this points to the potential for turbulent enhancement of collisioncoalescence to have an impact on precipitation in a wide variety of cloud types.

Of greater apparent importance are differences in spectral resolution, which influence the direction and magnitude of the effects of the turbulent kernel. Relative to the CTRL configurations, $\Delta d_{99}$ increases for LO TURB but decreases for HI TURB. The magnitude of the effect is also different for $R$ (larger increase for LO TURB than HI TURB), but this is likely due to the broader $\sigma$ produced by the HI configurations. For TO17, the profiles of $R$ are quite different for $\mathrm{LO}$ and $\mathrm{HI}$ bin resolution, but little surface accumulation occurs for any of the simulations. The counterintuitive result that the HI configurations produce broader spectra cannot be replicated in a parcel or box model; it is particular to the use of bin microphysics in an Eulerian framework. As an illustration, the tendency of the HI configurations to produce larger drops is opposite of that expected from the box model analysis of Tzivion et al. (1999), who find that finer bin resolution reduces numerical diffusion in the collision-coalescence scheme. Instead, the evidence for increased numerical diffusion due to collisioncoalescence in these simulations can be seen in the percentile diameter profiles (Figs. 10 and 11), where despite lower $\sigma$ in the LO simulations, the separation between HI- and LO-percentile diameters near the surface decreases from a maximum at $d_{50}$ [relative difference (HI CTRL - LO CTRL)/LO CTRL $=34 \%]$ to a minimum for $d_{99}$ (relative difference $13 \%$ ).

This study is not the first to acknowledge the difficulty of process-level attribution with respect to the impact of changing microphysics numerics (Grabowski 2014). The response of many other workers has been to remove microphysical feedbacks on dynamics (Pinsky et al. 2008; Grabowski 2014; Magaritz-Ronen et al. 2016), but the coupling of microphysics and dynamics in the presence of precipitation significantly alters the outcome of simulations and cannot be ignored (Stevens et al. 1998; Ackerman et al. 2004; Bretherton et al. 2007). Instead, the work presented here seeks to use observations as the standard for comparison while holding boundary conditions constant to allow the coupled microphysicaldynamical cloud system to respond in an admittedly more complex but physically relevant manner. The problem with using observations as the point of comparison is that many aspects of covariability in microphysics and meteorology are not captured by the LES. They either occur at temporal/spatial scales that cannot be simulated in LES, or they are simply not represented in the model physics (e.g., by using constant surface fluxes). As such, obtaining consistently good agreement between observations and LES results may ultimately be an unattainable goal. Despite this, the observations should still serve as the "ground truth," as they can meaningfully guide future work by demonstrating the shortcomings of the models designed to reproduce them.

Acknowledgments. This work was partially supported by the National Science Foundation under Grant AGS1139746. The authors thank Wojciech Grabowski for insightful comments on an earlier draft of the manuscript and three anonymous reviewers for comments and suggestions that improved the paper. MKW acknowledges support and computing resources from NCAR's Advanced Study Program and thanks Hugh Morrison and Jørgen Jensen for many fruitful discussions. NCAR is supported by the National Science Foundation. POST observations can be obtained freely from https://www. eol.ucar.edu/projects/post/. The bin microphysics code (https://www.esrl.noaa.gov/csd/staff/graham.feingold/code/) and the UCLA-LES code (http://github.com/uclales/) are available online.

\section{REFERENCES}

Ackerman, A. S., M. P. Kirkpatrick, D. E. Stevens, and O. B. Toon, 2004: The impact of humidity above stratiform clouds on indirect aerosol climate forcing. Nature, 432, 1014-1017, https:// doi.org/10.1038/nature03174.

_ stratocumulus-topped marine boundary layer. Mon. Wea. Rev., 137, 1083-1110, https://doi.org/10.1175/2008MWR2582.1.

Ayala, O., B. Rosa, L.-P. Wang, and W. Grabowski, 2008a: Effects of turbulence on the geometric collision rate of sedimenting droplets. Part 1: Results from direct numerical simulation. New J. Physics, 10, 075015, https://doi.org/10.1088/1367-2630/ 10/7/075015.

,,$-- \ldots$, and -2008 b: Effects of turbulence on the geometric collision rate of sedimenting droplets. Part 2: Theory and parameterization. New J. Physics, 10, 075016, https:// doi.org/10.1088/1367-2630/10/7/075016.

Baker, M. B., and J. Latham, 1979: The evolution of droplet spectra and the rate of production of embryonic raindrops in small cumulus clouds. J. Atmos. Sci., 36, 1612-1615, https://doi.org/ 10.1175/1520-0469(1979)036<1612:TEODSA > 2.0.CO;2.

Baumgardner, D., and A. Korolev, 1997: Airspeed corrections for optical array probe sample volumes. J. Atmos. Oceanic Technol., 14, 1224-1229, https://doi.org/10.1175/1520-0426(1997)014<1224: ACFOAP $>2$ 2.0.CO;2.

Beard, K., and H. Ochs, 1993: Warm-rain initiation: An overview of microphysical mechanisms. J. Appl. Meteor., 32, 608-625, https:// doi.org/10.1175/1520-0450(1993)032<0608:WRIAOO > 2.0.CO;2. 
Benmoshe, N., M. Pinsky, A. Pokrovsky, and A. Khain, 2012: Turbulent effects on the microphysics and initiation of warm rain in deep convective clouds: 2-D simulations by a spectral mixed-phase microphysics cloud model. J. Geophys. Res., 117, D06220, https://doi.org/10.1029/2011JD016603.

Bretherton, C. S., P. N. Blossey, and J. Uchida, 2007: Cloud droplet sedimentation, entrainment efficiency, and subtropical stratocumulus albedo. Geophys. Res. Lett., 34, L03813, https:// doi.org/10.1029/2006GL027648.

Carman, J. K., D. L. Rossiter, D. Khelif, H. H. Jonsson, I. C. Faloona, and P. Y. Chuang, 2012: Observational constraints on entrainment and the entrainment interface layer in stratocumulus. Atmos. Chem. Phys., 12, 11 135-11 152, https:// doi.org/10.5194/acp-12-11135-2012.

Chen, S., P. Bartello, M. K. Yau, P. A. Vaillancourt, and K. Zwijsen, 2016: Cloud droplet collisions in turbulent environment: Collision statistics and parameterization. J. Atmos. Sci., 73, 621-636, https://doi.org/10.1175/JAS-D-15-0203.1.

Chuang, P. Y., E. W. Saw, J. D. Small, R. A. Shaw, C. M. Sipperley, G. A. Payne, and W. D. Bachalo, 2008: Airborne phase Doppler interferometry for cloud microphysical measurements. Aerosol Sci. Technol., 42, 685-703, https://doi.org/10.1080/02786820802232956.

Clark, T. L., 1973: Numerical modeling of the dynamics and microphysics of warm cumulus convection. J. Atmos. Sci., 30, 857-878, https://doi.org/10.1175/1520-0469(1973)030<0857: NMOTDA $>2.0 . \mathrm{CO} ; 2$.

Cooper, W. A., S. G. Lasher-Trapp, and A. M. Blyth, 2013: The influence of entrainment and mixing on the initial formation of rain in a warm cumulus cloud. J. Atmos. Sci., 70, 1727-1743, https://doi.org/10.1175/JAS-D-12-0128.1.

Devenish, B., and Coauthors, 2012: Droplet growth in warm turbulent clouds. Quart. J. Roy. Meteor. Soc., 138, 1401-1429, https://doi.org/10.1002/qj.1897.

Franklin, C., 2008: A warm rain microphysics parameterization that includes the effect of turbulence. J. Atmos. Sci., 65, 17951816, https://doi.org/10.1175/2007JAS2556.1.

Gerber, H., G. Frick, S. P. Malinowski, H. Jonsson, D. Khelif, and S. K. Krueger, 2013: Entrainment rates and microphysics in POST stratocumulus. J. Geophys. Res. Atmos., 118, 12094 12109, https://doi.org/10.1002/jgrd.50878.

Grabowski, W. W., 2014: Extracting microphysical impacts in large-eddy simulations of shallow convection. J. Atmos. Sci., 71, 4493-4499, https://doi.org/10.1175/JAS-D-14-0231.1.

- , and H. Morrison, 2008: Toward the mitigation of spurious cloud-edge supersaturation in cloud models. Mon. Wea. Rev., 136, 1224-1234, https://doi.org/10.1175/2007MWR2283.1.

— bulent environment. Annu. Rev. Fluid Mech., 45, 293-324, https://doi.org/10.1146/annurev-fluid-011212-140750.

Hall, W., 1980: A detailed microphysical model within a twodimensional dynamic framework: Model description and preliminary results. J. Atmos. Sci., 37, 2486-2507, https://doi.org/ 10.1175/1520-0469(1980)037<2486:ADMMWA > 2.0.CO;2.

Hudson, J. G., and G. Svensson, 1995: Cloud microphysical relationships in California marine stratus. J. Atmos. Sci., 34, 2655-2666, https://doi.org/10.1175/1520-0450(1995)034<2655: CMRICM $>2.0 . \mathrm{CO} ; 2$.

IPCC, 2013: Climate Change 2013: The Physical Science Basis. Cambridge University Press, 1535 pp., https://doi.org/10.1017/ CBO9781107415324.

Jen-La Plante, I., and Coauthors, 2016: Physics of Stratocumulus Top (POST): Turbulence characteristics. Atmos. Chem. Phys., 16, 9711-9725, https://doi.org/10.5194/acp-16-9711-2016.
Jensen, J. B., and A. D. Nugent, 2017: Condensational growth of drops formed on giant sea-salt aerosol particles. J. Atmos. Sci., 74, 679-697, https://doi.org/10.1175/JAS-D-15-0370.1.

Johnson, D. B., 1982: The role of giant and ultragiant aerosol particles in warm rain initiation. J. Atmos. Sci., 39, 448-460, https://doi.org/10.1175/1520-0469(1982)039<0448:TROGAU> 2.0.CO;2.

Khain, A. P., and Coauthors, 2015: Representation of microphysical processes in cloud-resolving models: Spectral (bin) microphysics versus bulk parameterization. Rev. Geophys., 53, 247-322, https://doi.org/10.1002/2014RG000468.

Khairoutdinov, M. F., and Y. L. Kogan, 1999: A large eddy simulation model with explicit microphysics: Validation against aircraft observations of a stratocumulus-topped boundary layer. J. Atmos. Sci., 56, 2115-2131, https://doi.org/10.1175/ 1520-0469(1999)056<2115:ALESMW>2.0.CO;2.

—_, and — 2000: A new cloud physics parameterization in a large-eddy simulation model of marine stratocumulus. Mon. Wea. Rev., 128, 229-243, https://doi.org/10.1175/15200493(2000)128<0229:ANCPPI>2.0.CO;2.

Korolev, A., 2007: Reconstruction of the sizes of spherical particles from their shadow images. Part I: Theoretical considerations. J. Atmos. Oceanic Technol., 24, 376-389, https://doi.org/10.1175/ JTECH1980.1.

Liu, Y., and P. H. Daum, 2000: Spectral dispersion of cloud droplet size distributions and the parameterization of cloud droplet effective radius. Geophys. Res. Lett., 27, 1903-1906, https:// doi.org/10.1029/1999GL011011.

Lu, M. L., W. C. Conant, H. H. Jonsson, V. Varutbangkul, R. C. Flagan, and J. H. Seinfeld, 2007: The Marine Stratus/Stratocumulus Experiment (MASE): Aerosol-cloud relationships in marine stratocumulus. J. Geophys. Res., 112, D10209, https://doi.org/ 10.1029/2006JD007985.

Magaritz-Ronen, L., M. Pinsky, and A. Khain, 2016: Drizzle formation in stratocumulus clouds: Effects of turbulent mixing. Atmos. Chem. Phys., 16, 1849-1862, https://doi.org/10.5194/ acp-16-1849-2016.

Martin, G. M., D. W. Johnson, and A. Spice, 1994: The measurement and parameterization of effective radius of droplets in warm stratocumulus clouds. J. Atmos. Sci., 51, 1823-1842, https://doi.org/10.1175/1520-0469(1994)051<1823:TMAPOE> 2.0.CO;2.

McClatchy, R. A., R. W. Fenn, J. E. A. Selby, F. E. Volz, and J. S. Garing, 1971: Optical properties of the atmosphere. Air Force Cambridge Research Laboratories Environmental Research Paper 411, 113 pp.

Morrison, H., M. Witte, G. H. Bryan, J. Y. Harrington, and Z. J. Lebo, 2018: Broadening of modeled cloud droplet spectra using bin microphysics in an Eulerian spatial domain. J. Atmos. Sci., 75, 4005-4030, https://doi.org/10.1175/JASD-18-0055.1.

Onishi, R., and A. Seifert, 2016: Reynolds-number dependence of turbulence enhancement on collision growth. Atmos. Chem. Phys., 16, 12 441-12 455, https://doi.org/10.5194/acp-1612441-2016.

Pawlowska, H., W. W. Grabowski, and J.-L. Brenguier, 2006: Observations of the width of cloud droplet spectra in stratocumulus. Geophys. Res. Lett., 33, L19810, https://doi.org/ 10.1029/2006GL026841.

Pincus, R., and B. Stevens, 2009: Monte Carlo spectral integration: A consistent approximation for radiative transfer in large eddy simulations. J. Adv. Model. Earth Syst., 1, 1, https://doi.org/ 10.3894/JAMES.2009.1.1. 
Pinsky, M., L. Magaritz, A. Khain, O. Krasnov, and A. Sterkin, 2008: Investigation of droplet size distributions and drizzle formation using a new trajectory ensemble model. Part I: Model description and first results in a nonmixing limit. J. Atmos. Sci., 65, 2064-2086, https://doi.org/10.1175/ 2007JAS2486.1.

Rémillard, J., and Coauthors, 2017: Use of cloud radar Doppler spectra to evaluate stratocumulus drizzle size distributions in large-eddy simulations with size-resolved microphysics. J. Appl. Meteor. Climatol., 56, 3263-3283, https://doi.org/ 10.1175/JAMC-D-17-0100.1.

Seifert, A., L. Nuijens, and B. Stevens, 2010: Turbulence effects on warm-rain autoconversion in precipitating shallow convection. Quart. J. Roy. Meteor. Soc., 136, 1753-1762, https:// doi.org/10.1002/qj.684.

Siebert, H., R. Shaw, and Z. Warhaft, 2010: Statistics of small-scale velocity fluctuations and internal intermittency in marine stratocumulus clouds. J. Atmos. Sci., 67, 262-273, https://doi.org/ 10.1175/2009JAS3200.1.

Stevens, B., and A. Seifert, 2008: Understanding macrophysical outcomes of microphysical choices in simulations of shallow cumulus convection. J. Meteor. Soc. Japan, 86A, 143-162, https://doi.org/10.2151/jmsj.86A.143.

_ , G. Feingold, W. R. Cotton, and R. L. Walko, 1996a: Elements of the microphysical structure of numerically simulated nonprecipitating stratocumulus. J. Atmos. Sci., 53, 980-1006, https://doi.org/10.1175/1520-0469(1996)053<0980:EOTMSO> 2.0.CO;2.

_ R. L. Walko, W. R. Cotton, and G. Feingold, 1996b: The spurious production of cloud-edge supersaturations by Eulerian models. Mon. Wea. Rev., 124, 1034-1041, https:/doi.org/10.1175/ 1520-0493(1996)124<1034:TSPOCE > 2.0.CO;2.

, W. R. Cotton, G. Feingold, and C.-H. Moeng, 1998: Large-eddy simulations of strongly precipitating, shallow, stratocumulus-topped boundary layers. J. Atmos. Sci., 55, 3616-3638, https://doi.org/10.1175/1520-0469(1998)055<3616: LESOSP $>2.0 . \mathrm{CO} ; 2$.

Strapp, J. W., F. Albers, A. Reuter, A. V. Korolev, U. Maixner, E. Rashke, and Z. Vukovic, 2001: Laboratory measurements of the response of a PMS OAP-2DC. J. Atmos. Oceanic Technol., 18, 1150-1170, https://doi.org/10.1175/1520-0426(2001)018<1150: LMOTRO $>2.0 . \mathrm{CO} ; 2$.

Tzivion, S., G. Feingold, and Z. Levin, 1987: An efficient numerical solution to the stochastic collection equation. J. Atmos. Sci., 44, 3139-3149, https://doi.org/10.1175/1520-0469(1987) 044<3139:AENSTT>2.0.CO;2.

,-- , and -1989 : The evolution of raindrop spectra. Part II: Collisional collection/breakup and evaporation in a rainshaft. J. Atmos. Sci., 46, 3312-3328, https://doi.org/10.1175/ 1520-0469(1989)046<3312:TEORSP > 2.0.CO;2.

_ T. G. Reisin, and Z. Levin, 1999: A numerical solution of the kinetic collection equation using high spectral grid resolution: A proposed reference. J. Comput. Phys., 148, 527-544, https:// doi.org/10.1006/jcph.1998.6128.

Wang, L.-P., and W. Grabowski, 2009: The role of air turbulence in warm rain initiation. Atmos. Sci. Lett., 10, 1-8, https://doi.org/ 10.1002/asl.210.

Witte, M. K., O. Ayala, L. P. Wang, A. Bott, and P. Y. Chuang, 2017: Estimating collision-coalescence rates from in situ observations of marine stratocumulus. Quart. J. Roy. Meteor. Soc., 143, 2755-2763, https://doi.org/10.1002/qj.3124.

Wood, R., 2006: Rate of loss of cloud droplets by coalescence in warm clouds. J. Geophys. Res., 111, D21205, https://doi.org/ 10.1029/2006JD007553.

Wyszogrodzki, A. A., W. W. Grabowski, L.-P. Wang, and O. Ayala, 2013: Turbulent collision-coalescence in maritime shallow convection. Atmos. Chem. Phys., 13, 8471-8487, https://doi.org/ 10.5194/acp-13-8471-2013. 